Atmos. Chem. Phys., 17, 13833-13848, 2017

https://doi.org/10.5194/acp-17-13833-2017

(C) Author(s) 2017. This work is distributed under

the Creative Commons Attribution 3.0 License.

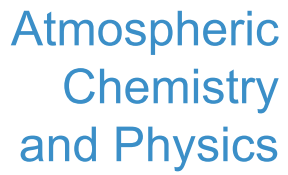

(c) (P)

\title{
Sensitivity of surface temperature to radiative forcing by contrail cirrus in a radiative-mixing model
}

\author{
Ulrich Schumann $^{1}$ and Bernhard Mayer ${ }^{2}$ \\ ${ }^{1}$ Deutsches Zentrum für Luft- und Raumfahrt, Institut für Physik der Atmosphäre, Oberpfaffenhofen, Germany \\ ${ }^{2}$ Ludwig-Maximilians-Universität München, Lehrstuhl für Experimentelle Meteorologie, Munich, Germany \\ Correspondence to: Ulrich Schumann (ulrich.schumann@dlr.de)
}

Received: 16 May 2017 - Discussion started: 29 May 2017

Revised: 6 October 2017 - Accepted: 18 October 2017 - Published: 21 November 2017

\begin{abstract}
Earth's surface temperature sensitivity to radiative forcing (RF) by contrail cirrus and the related RF efficacy relative to $\mathrm{CO}_{2}$ are investigated in a one-dimensional idealized model of the atmosphere. The model includes energy transport by shortwave (SW) and longwave (LW) radiation and by mixing in an otherwise fixed reference atmosphere (no other feedbacks). Mixing includes convective adjustment and turbulent diffusion, where the latter is related to the vertical component of mixing by large-scale eddies. The conceptual study shows that the surface temperature sensitivity to given contrail RF depends strongly on the timescales of energy transport by mixing and radiation. The timescales are derived for steady layered heating (ghost forcing) and for a transient contrail cirrus case. The radiative timescales are shortest at the surface and shorter in the troposphere than in the midstratosphere. Without mixing, a large part of the energy induced into the upper troposphere by radiation due to contrails or similar disturbances gets lost to space before it can contribute to surface warming. Because of the different radiative forcing at the surface and at top of atmosphere (TOA) and different radiative heating rate profiles in the troposphere, the local surface temperature sensitivity to stratosphere-adjusted RF is larger for SW than for LW contrail forcing. Without mixing, the surface energy budget is more important for surface warming than the TOA budget. Hence, surface warming by contrails is smaller than suggested by the net RF at TOA. For zero mixing, cooling by contrails cannot be excluded. This may in part explain low efficacy values for contrails found in previous global circulation model studies. Possible implications of this study are discussed. Since the results of this study are model dependent, they should be tested with a comprehensive climate model in the future.
\end{abstract}

\section{Introduction}

Contrails are similar to upper-tropospheric ice clouds (cirrus), which tend to warm the troposphere by reducing outgoing longwave (LW) terrestrial radiation and cool it by enhancing shortwave (SW) solar radiation backscattering (Stephens and Webster, 1981; Liou, 1986; Sinha and Shine, 1994; Chen et al., 2000; Schumann and Heymsfield, 2017). For low optical thickness, the net cloud radiative forcing (RF) from cirrus is often positive at top of the atmosphere (TOA) but negative at the surface (Ackerman et al., 1988; Stackhouse and Stephens, 1991; Fu and Liou, 1993; Jensen et al., 1994; Rossow and Zhang, 1995; Meerkötter et al., 1999; Kvalevåg and Myhre, 2007; Dietmüller et al., 2008; J. Lee et al., 2009; Allan, 2011; Berry and Mace, 2014; Hong et al., 2016). For well-mixed greenhouse gases, a positive RF implies a global warming (Shine et al., 1994; Hansen et al., 1997a). However, cirrus induces a radiative heat source profile which tends to warm the upper troposphere but may cool the surface (Liou, 1986). Heat induced by radiation in the upper troposphere must be transported downwards to contribute to surface warming, e.g., by convective, baroclinic, and other dynamical mixing processes (Manabe and Wetherald, 1967; Stone, 1973; Vallis, 2006). Hence, the question of whether cirrus clouds cool or warm the Earth's surface cannot be simply answered from studies of radiative flux changes alone.

The sensitivity of surface temperature to contrail cirrus changes is relevant with respect to aviation climate impact (D. S. Lee et al., 2009; Boucher et al., 2013; Lund et al., 2017). Long-lived contrails of significant optical thickness $(>0.1)$ are estimated to cover about $0.2-0.5 \%$ of the Earth, with higher values in northern midlatitudes (Minnis et al., 2013; Schumann et al., 2015; Bock and Burkhardt, 2016). 
Early studies expected a regional surface cooling from contrails (Reinking, 1968). Later, a hemispheric atmosphere warming by contrails was derived from models (Liou et al., 1990). A special report on Global Aviation of the Intergovernmental Panel on Climate Change (IPCC) (Penner et al., 1999) concluded in 1999 that "contrails tend to warm the Earth's surface, similar to high clouds". Observational evidence for contrail warming is missing because the expected changes are small and not well correlated with contrail cover, and observed changes may have many causes (Minnis, 2005). Contrail RF contributions depend on many contrail and Earth-atmosphere system properties (Meerkötter et al., 1999; Minnis et al., 1999; Myhre and Stordal, 2001; Schumann et al., 2012). Contrails are composed of relatively small and aspherical ice particles (Gayet et al., 2012). Hence, contrails may favor the albedo cooling over the greenhouse warming effect (Fu and Liou, 1993; Strauss et al., 1997; Wyser and Ström, 1998; Zhang et al., 1999; Marquart et al., 2003; Wendisch et al., 2005; Markowicz and Witek, 2011; Bi and Yang, 2017). Contrail contributions to TOA cloud forcings have been derived from observations (Schumann and Graf, 2013; Spangenberg et al., 2013; VázquezNavarro et al., 2015). Most traffic occurs during daytime causing contrails with higher SW fraction. The global mean positive LW and negative SW parts may be nearly canceling each other with a small positive net RF at TOA. Local increases in LW fluxes below contrails are hardly measurable because tropospheric water vapor shields the surface partly from contrail-induced LW flux changes (Kuhn, 1970). Local reductions in SW fluxes are easily observable at the surface (Khvorostyanov and Sassen, 1998; Haywood et al., 2009; Weihs et al., 2015). Hence, contrails may have the potential to cool (Sassen, 1997).

The global mean equilibrium change of near-surface air temperature is often approximated by $\Delta T_{\mathrm{S}}=\lambda \mathrm{RF}$ as a function of the net downward flux change RF at the tropopause and a "climate sensitivity parameter", $\lambda$ (Houghton et al., 1990). $\lambda$ is similar to the planetary temperature sensitivity parameter $\lambda_{\mathrm{p}}$ to changes in solar irradiance (Stephens, 2005), $\lambda_{\mathrm{p}}=\left[1 /\left(4 \sigma T_{\mathrm{s}}^{3}\right)\right]\left(T_{\mathrm{s}} / T_{\mathrm{p}}\right)^{3}\left[\mathrm{~d} T_{\mathrm{s}} / \mathrm{d} T_{\mathrm{p}}\right]$. Here $\sigma$ is the StefanBoltzmann constant, $T_{\mathrm{s}}$ is the surface temperature, and $T_{\mathrm{p}}$ is the effective temperature of planetary infrared emissions, $\sigma T_{\mathrm{p}}^{4} \cong S_{0}(1-a) / 4$, with solar irradiance $S_{0} \cong 1360 \mathrm{~W} \mathrm{~m}^{-2}$ and Earth albedo $a \cong 0.3$. Hence, $\lambda_{\mathrm{p}} \cong 0.267 \mathrm{~K} \mathrm{~W}^{-1} \mathrm{~m}^{2}$ for $\left[\mathrm{d} T_{\mathrm{s}} / \mathrm{d} T_{\mathrm{p}}\right]=1$. The feedback factor $\left[\mathrm{d} T_{\mathrm{s}} / \mathrm{d} T_{\mathrm{p}}\right]$ differs from 1 depending on the various forcing types (Stephens, 2005; Bony et al., 2006; Stevens and Bony, 2013). Therefore, $\lambda$ is not a universal constant (Forster et al., 1997; Joshi et al., 2003; Stuber et al., 2005). The "efficacy" $e=\lambda_{\mathrm{c}} / \lambda_{\mathrm{CO}_{2}}$, i.e., the ratio of climate sensitivities $\lambda_{\mathrm{c}}$ for non- $\mathrm{CO}_{2}$ disturbances and $\lambda_{\mathrm{CO}_{2}}$ for a given change in $\mathrm{CO}_{2}$, generally differs from 1 (Hansen et al., 2005). Various alternative RF definitions have been suggested to improve the link to climate sensitivity (Boucher et al., 2013; Myhre et al., 2013). The instantaneous
$\mathrm{RF}_{\mathrm{i}}$ is the RF for a fixed atmosphere. The adjusted $\mathrm{RF}_{\mathrm{a}}$ is the RF after thermal relaxation of the stratosphere to the disturbance (Houghton et al., 1990; Stuber et al., 2001). The effective $\mathrm{RF}_{\mathrm{S}}$ is the RF after adjustment of the atmosphere to disturbances for constant (ocean) surface temperature (Rotstayn and Penner, 2001; Hansen et al., 2002; Shine et al., 2003).

Since air traffic is projected to continue to increase for many decades, it is important to know the climate impact of contrails accurately (D. S. Lee et al., 2009). Various models to represent contrails in three-dimensional atmospheric global circulation models have been developed (Ponater et al., 1996; Rind et al., 2000; Ponater et al., 2002; Marquart et al., 2003; Rap et al., 2010b; Burkhardt and Kärcher, 2011; Jacobson et al., 2011; Olivié et al., 2012; Chen and Gettelman, 2013; Schumann et al., 2015; Bock and Burkhardt, 2016), with different treatments of traffic, subgrid-scale contrail formation, and optical properties. Some of these models were run with atmosphere-ocean coupling (Rind et al., 2000; Ponater et al., 2005; Rap et al., 2010a; Huszar et al., 2013; Jacobson et al., 2013). The contrail climate effects are expensive to compute because they are small compared to the interannual variability ("climate noise") in climate models (Ponater et al., 1996; Hansen et al., 1997b), so most studies used increased disturbances by a factor of 10 to 100 . All these model studies suggest a mean global warming from contrails. The contrail efficacy has been computed in a few studies, with results varying from 0.3 to 1 (Hansen et al., 2005; Ponater et al., 2005; Rap et al., 2010a).

The classical RF concept assumes that the surface temperature response follows the TOA energy budget change (Schneider and Dickinson, 1974; Dickinson, 1982). This requires that the energy induced by the disturbance be well mixed globally within the troposphere and down to the surface. In order to be effective for a long-term ocean warming, the mixing has to occur at timescales fast compared to the timescale of heat loss from the atmosphere to space by radiation. Temperature profile disturbances within the atmosphere relax by thermal relaxation with timescales which are of the order of hours to months depending, among others, on altitude, vertical disturbance scales, and mixing (Manabe and Strickler, 1964; Zhu, 1993). Mainly because of denser air traffic, most contrails occur at midlatitudes. At midlatitudes, mixing is mainly driven by baroclinic instability in the stably stratified, rotating atmosphere but also depends on moisture, leading to large-scale eddies transporting heat from the tropics poleward and upward (Stone, 1973). The baroclinic mixing occurs at timescales of several days (Vallis, 2006). Hence, mixing at midlatitudes is slower than in convective parts of the tropics where deep convection in clouds causes fast vertical heat transport (Wetherald and Manabe, 1975). Again because of denser traffic, contrails occur mainly over land. It is unclear whether the heat induced radiatively by contrails in the troposphere over land reaches the ocean by 
horizontal advection and downward mixing before getting lost to space by radiation.

In this conceptual study, we investigate changes in temperature from additional thin cirrus (contrails) at midlatitudes in a radiative-mixing model where the vertical mixing may result from deep convection, from the large-scale circulation, and from turbulent diffusion. For better understanding, the model is run without climate system changes ("feedbacks"; Manabe and Wetherald, 1967) other than thermal relaxation by radiation and mixing. The model is run with highly idealized surface conditions (to minimize the number of free parameters), including constant temperature and zero net vertical heat flux at the surface ("adiabatic surface") as bounding extremes. Instead of investigating the approach to equilibrium with ocean coupling, we simulate the equilibrium atmosphere without heat exchange to an underlying compartment. The disturbances considered are small and, hence, change the reference atmosphere only slightly. For this reason the model is run with fixed dynamical heating, simulating the heat sources, e.g., from horizontal heat advection, as required for a steady-state reference atmosphere (Strauss et al., 1997). The optical properties of cirrus are essential for its radiative forcing ( $\mathrm{Fu}, 1996$; Myhre et al., 2009; Yang et al., 2015), but for this study the cirrus is just a source of SW and LW radiation flux-profile changes with cloud-radiation interaction details of secondary relevance. Other clouds and aerosols are not included in this study. The method is described in Sect. 2. Section 3 presents the results. Section 3.1 shows the responses of an idealized atmosphere to prescribed heating, so-called "ghost forcing". This part will point out the importance of the vertical distribution of the radiative heat sources and vertical mixing. The thermal response to a prescribed contrail cirrus layer is studied in Sect. 3.2. We separate the temperature responses to SW and LW radiative disturbances by contrails and refer correspondingly to " $\mathrm{SW}$ cirrus" (similar to layer of small and non-absorbing particles) and "LW cirrus" (similar to a strong greenhouse gas layer). For constant atmosphere, the sum of SW and LW RF from these cirrus versions is the same as the net RF. This part will show different temperature responses to SW and LW radiative forcing. A study of thermal relaxation times for contrail cirrus will show up some consequences of temporally and spatially variable contrails. For comparison and for computation of efficacies for contrails relative to $\mathrm{CO}_{2}$, we run the same model for changed $\mathrm{CO}_{2}$. Finally, Sect. 4 summarizes the approach, the results, and the limitations and mentions some implications.

\section{Radiative-convective and radiative-diffusive mixing model}

This study uses a one-dimensional radiative-mixing model of the atmosphere with prescribed composition and clouds, following traditional approaches (Möller and Manabe, 1961;
Manabe and Strickler, 1964) with turbulent fluxes as in Ramanathan and Coakley (1978).

The model is integrated step-wise in time until steady state. It computes the temperature profile $T(z, t)$ versus altitude $z$ and time $t$ as induced by radiative and turbulent heat transports, based on the heat budget:

$\rho c_{p} \frac{\partial T}{\partial t}=-\frac{\partial F_{\mathrm{R}}}{\partial z}-\frac{\partial F_{\mathrm{T}}}{\partial z}+Q_{0}$,

$F_{\mathrm{R}}=F_{\mathrm{SW}}^{\mathrm{up}}-F_{\mathrm{SW}}^{\mathrm{dn}}+F_{\mathrm{LW}}^{\mathrm{up}}-F_{\mathrm{LW}}^{\mathrm{dn}}$,

$F_{\mathrm{T}}=-\rho c_{p} \kappa\left(\frac{\partial T}{\partial z}+\Gamma\right)$.

Here, $\rho$ and $c_{p}$ are air density and isobaric specific heat capacity, $F_{\mathrm{R}}$ is the net radiative flux (sum of upward and downward SW and LW fluxes), $F_{\mathrm{T}}$ is the turbulent heat flux, $\Gamma$ is a prescribed threshold lapse rate, and $\kappa=\kappa(t, z)$ is a turbulent diffusivity selected to approximate diffusive mixing (constant $\kappa$ ) or convective adjustment (large $\kappa$ in case of unstable stratification), as explained below. For contrails and for other small disturbances we compute the temperature change profile $\Delta T(t, z)=T(t, z)-T_{0}(z)$ in a given reference atmosphere with temperature profile $T_{0}(z)$, i.e., we run the model with "fixed dynamical heating" $Q_{0}$. Here, $Q_{0}=$ $\partial\left(F_{\mathrm{R}}+F_{\mathrm{T}}\right) / \partial z$ is the divergence of the total flux for $T=T_{0}$, so that the undisturbed reference atmosphere is steady. Fixed dynamical heating is commonly used for stratospheric adjustment (Ramanathan and Dickinson, 1979; Forster et al., 1997; Myhre et al., 1998). Here we use fixed dynamical heating to study the atmosphere response for a given reference atmosphere to small disturbances (Strauss et al., 1997).

The radiative flux $F_{\mathrm{R}}$ is computed with an efficient deltaEddington two-stream solver using libRadtran (Mayer and Kylling, 2005; Emde et al., 2016), which is a common solver for climate model applications. Tests with the more accurate discrete ordinate solver DISORT (Stamnes et al., 1998) show flux differences relative to the two-stream solver of about $10 \%$, mainly in the LW range. Radiation absorption by gases $\left(\mathrm{H}_{2} \mathrm{O}, \mathrm{CO}_{2}, \mathrm{O}_{3}\right.$, etc. $)$ is calculated with correlated $\mathrm{K}$ distributions for $\mathrm{SW}(\sim 0.2-4 \mu \mathrm{m})$ and $\mathrm{LW}$ radiation $(4-70 \mu \mathrm{m})$ from $\mathrm{Fu}$ and Liou (1992). An alternative SW absorption model from Kato et al. (1999) induces flux differences small compared to those between the two solvers. The model includes a cirrus layer of hexagonal ice crystals with optical properties from $\mathrm{Fu}$ (1996) and Fu et al. (1998).

The turbulent flux $F_{\mathrm{T}}$ is approximated as a function of a linearized potential temperature gradient $\mathrm{d} T / \mathrm{d} z-\Gamma$ including the prescribed lapse rate $\Gamma$, and diffusivity $\kappa$ (Ramanathan and Coakley, 1978; Liou and Ou, 1983). The inclusion of $\Gamma$ ensures that an atmosphere under threshold conditions with $\mathrm{d} T / \mathrm{d} z=-\Gamma$ experiences zero turbulent fluxes. The diffusivity $\kappa$ is set to zero in the stratosphere and to a constant $\kappa=100 \mathrm{~m}^{2} \mathrm{~s}^{-1}$ in the troposphere for simulation of diffusive mixing in this study. Liou and Ou (1983) used values up to $200 \mathrm{~m}^{2} \mathrm{~s}^{-1}$ to simulate cirrus in the tropical atmo- 
sphere. The diffusivity $\kappa$ causes vertical mixing in the troposphere with timescales $L_{\mathrm{v}}^{2} / \kappa$ depending on vertical scales $L_{\mathrm{v}}$ of temperature changes, about 10 days for mixing over the whole troposphere $\left(L_{\mathrm{V}} \approx 10 \mathrm{~km}\right)$ and about $3 \mathrm{~h}$ for a layer of $1 \mathrm{~km}$ depth. Stone (1973) estimates the effective diffusivity $\kappa_{\mathrm{H}}$ for horizontal mixing by large-scale eddies to be at least $10^{6} \mathrm{~m}^{2} \mathrm{~s}^{-1}$. For similar timescales, the diffusivity $\kappa$ for vertical mixing should be related to $\kappa_{\mathrm{H}}$ by the square of the ratio of vertical to horizontal length scales. The lengthscale ratio can be estimated from geostrophic equilibrium, $L_{\mathrm{V}} / L_{\mathrm{H}} \approx f / N$, where $f$ and $N$ are the Coriolis and the Brunt-Väisälä frequencies (Vallis, 2006). For typical midlatitude and tropospheric values $\left(f=10^{-4} \mathrm{~s}^{-1}, N=0.01 \mathrm{~s}^{-1}\right)$ one obtains $\kappa \approx\left(L_{\mathrm{V}} / L_{\mathrm{H}}\right)^{2} \kappa_{\mathrm{H}} \approx 100 \mathrm{~m}^{2} \mathrm{~s}^{-1}$. These are, of course, order of magnitude estimates.

Various methods have been used in the past for "convective adjustment", i.e., enforcement of the lapse rate below a given threshold of, e.g., $\Gamma=6.5 \mathrm{~K} \mathrm{~km}^{-1}$ (Manabe and Strickler, 1964; Ramanathan and Coakley, 1978). Here, we increase the diffusivities by the factor $100(2 / \pi) \operatorname{atan}(\gamma)$, with $\gamma=\max \left[0,-(\Gamma+\mathrm{d} T / \mathrm{d} z) / \Gamma_{\mathrm{t}}\right]$, allowing for a small departure of $-\mathrm{d} T / \mathrm{d} z$ from the threshold lapse rate $\Gamma$ by setting $\Gamma_{\mathrm{t}}$ to $0.1 \mathrm{~K} \mathrm{~km}^{-1}$. This causes rapid convective adjustment at timescales shorter than one time step $(6 \mathrm{~h})$ and avoids spurious numerical oscillations from the on-off behavior of convection near threshold conditions. The method provides a well-defined turbulent flux, avoids iterations, is numerically stable, and conserves thermal energy.

The numerical scheme uses a nonuniform grid in $\mathrm{z}$ with model TOA at $60 \mathrm{~km}$ with 100 grid layers or cells vertically. High vertical resolution is necessary to resolve the local flux changes caused by thin cloud layers. The lowest layer is centered at $25 \mathrm{~m}$, the highest at $57.5 \mathrm{~km}$, about $0.3 \mathrm{hPa}$; the grid spacing is $\Delta z=250 \mathrm{~m}$ between 0.25 and $19 \mathrm{~km}$ height. The radiative solver gets the air temperature and composition at grid centers together with the surface temperature as input and returns the fluxes at the grid cell boundaries as output. This staggering avoids $2 \Delta z$-wave artifacts. Diffusive fluxes are computed implicitly with a tridiagonal Gaussian solver based on the temperatures at the next time step. Pressure is recomputed after each change in temperature as a function of altitude for air as ideal gas assuming hydrostatic equilibrium for given gravitational acceleration and surface pressure $(1013 \mathrm{hPa})$. The tropopause is defined by the lowest grid interface with $\mathrm{d} T / \mathrm{d} z>-2 \mathrm{~K} \mathrm{~km}^{-1}$.

Initial conditions prescribe temperature and composition profiles for the midlatitude summer standard atmosphere without aerosols (Anderson et al., 1986), see Fig. 1. Surface albedo $(A=0.2)$, solar zenith angle $(\cos (\mathrm{SZA})=0.6$, $\mathrm{SZA}=53^{\circ}$ ), and daytime fraction (0.64) are selected for midlatitude summer conditions similar to other contrail studies (Meerkötter et al., 1999; Myhre et al., 2009). The $24 \mathrm{~h}$ mean TOA fluxes for these conditions are 525, 101, and $298 \mathrm{~W} \mathrm{~m}^{-2}$ for incident solar, reflected solar, and outgoing LW radiation, respectively. The dynamical heating $Q_{0}$ re-

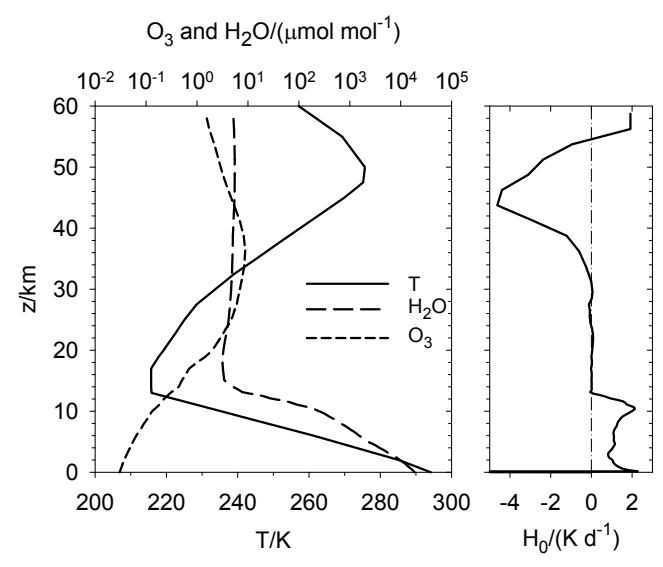

Figure 1. Temperature $T$ of the midlatitude summer standard atmosphere versus height $z$, together with water vapor and ozone molar mixing ratio $\left(\mathrm{O}_{2}: 0.2002 \mathrm{~mol} \mathrm{~mol}^{-1} ; \mathrm{CO}_{2}: 360 \mu \mathrm{mol} \mathrm{mol}^{-1}\right)$, and heating rate $H_{0}=Q_{0} /\left(\rho c_{p}\right)$ keeping the atmosphere at steady state. Because of TOA radiative imbalance, $H_{0}$ is strongly negative at the surface; in the mass-weighted average, $H_{0}=-1.25 \mathrm{~K} \mathrm{day}^{-1}$ in the troposphere and $-0.057 \mathrm{~K} \mathrm{day}^{-1}$ in the stratosphere, balancing the summer warming.

quired to keep the midlatitude summer atmosphere at steady state is shown in Fig. 1.

Boundary conditions prescribe either fixed surface temperature or an adiabatic boundary. An adiabatic boundary is implemented by setting $F_{\mathrm{R}}+F_{\mathrm{T}}=0$ at the surface. This flux is used when computing the heating rate in the lowest model layer. An adiabatic surface implies zero surface heat capacity and zero total flux between the atmosphere above and the compartment below the surface. This condition also simulates an atmosphere in thermal equilibrium with the lower compartment (ocean, ice, etc.). In this study, the surface temperature is set equal to the air temperature $T_{\mathrm{s}}$ in the lowest model layer, implying rapid energy exchange between the surface and the lowest air layer. The code runs stably with $6 \mathrm{~h}$ time steps for all applications in this paper.

The atmosphere responds to the radiative heating with changes of temperature (see Eq. 1) until the sum of the changed radiative and turbulent fluxes approach a vertically constant value. For constant surface temperature the fluxes stay nonzero. Over an adiabatic surface, the fluxes approach zero at all heights. During integration, we monitor the net vertical flux at all relevant altitudes (during stratospheric adjustment only in the stratosphere). The integration is performed until the maximum deviation of the flux values from the mean at all these altitudes is $<0.3 \%$ of the maximum instantaneous flux value.

RF is computed from the difference between the net total fluxes in model solutions with and without the disturbance. The sign of RF is defined such that positive values imply a warming of the Earth-troposphere system. The instantaneous (i), stratospheric-adjusted (a), and effective (s) 
forcing is computed from three model runs with different boundary conditions. $\mathrm{RF}_{\mathrm{i}}$ is the flux change for fixed atmosphere; it varies with height. $\mathrm{RF}_{\mathrm{a}}$ is the flux change at the tropopause after the stratosphere temperature has adjusted to the disturbance for fixed troposphere; it is constant throughout the stratosphere. The effective $\mathrm{RF}_{\mathrm{S}}$ is the flux change at the tropopause after reaching equilibrium in the entire atmosphere with fixed $T_{\mathrm{S}}$. Here, the total flux is vertically constant. Finally the equilibrium response is computed for an adiabatic surface for which the total flux change is zero at all levels.

The method has been tested with the mentioned alternative solvers and molecular absorption models by comparison of the daily-mean and the time-dependent instantaneous SW and LW RF values of a contrail layer with results from earlier studies (Meerkötter et al., 1999); see Figs. 2 and 3. For zero dynamical heating, the code reproduces the approach to radiative equilibrium in the atmosphere as in Manabe and Strickler (1964). For a doubled $\mathrm{CO}_{2}$ mixing ratio (from 300 to $600 \mu \mathrm{mol} \mathrm{mol}^{-1}$ ), the model computes a temperature change of $1.1 \mathrm{~K}$ without feedbacks, similar to previous results (Hansen et al., 1981).

\section{Results and discussions}

\subsection{Temperature response to prescribed heating at various altitude levels}

In order to understand air and surface temperature responses to heating at various altitudes, we follow the ghost forcing concept of Hansen et al. (1997a). The ghost forcing is a prescribed additive flux change causing a constant heating rate in an altitude interval. The heating causes temperature changes until reaching equilibrium, in which the changed fluxes balance the ghost forcing. Eleven simulations are performed with a prescribed flux change of $1 \mathrm{~W} \mathrm{~m}^{-2}$. One simulation is run for a flux change in the lowest model layer above the surface, and 10 for flux changes in subsequent $100 \mathrm{hPa}$ pressure intervals between the surface and TOA. The imposed change in net flux is zero at the surface, without direct impact on surface heating, and decreases linearly from 0 to $-1 \mathrm{~W} \mathrm{~m}^{-2}$ within the heated atmosphere interval. Above the heated layer, the flux change is constant so that $\mathrm{RF}_{\mathrm{i}}=1 \mathrm{~W} \mathrm{~m}^{-2}$ at TOA. Because of equal masses, the heating rate $H=g\left(\partial F_{\mathrm{R}} / \partial p\right) / c_{p}=0.083 \mathrm{~K} \mathrm{day}^{-1}$ is constant in the respective $100 \mathrm{hPa}$ intervals but $0.24 \mathrm{~K} \mathrm{day}^{-1}$ in the thinner lowest layer for surface ghost forcing. Figure 4 shows, for example, the heating profile for forcing between 600 and $700 \mathrm{hPa}$. Figure 5 shows the initial and final flux profiles versus height for the disturbances considered in this paper. We find that the flux in equilibrium over a constant-temperature surface is in between the initial instantaneous flux values at the tropopause and at the surface.

Figure 6 shows the steady-state temperature profiles versus pressure altitude in response to the 11 ghost forcings

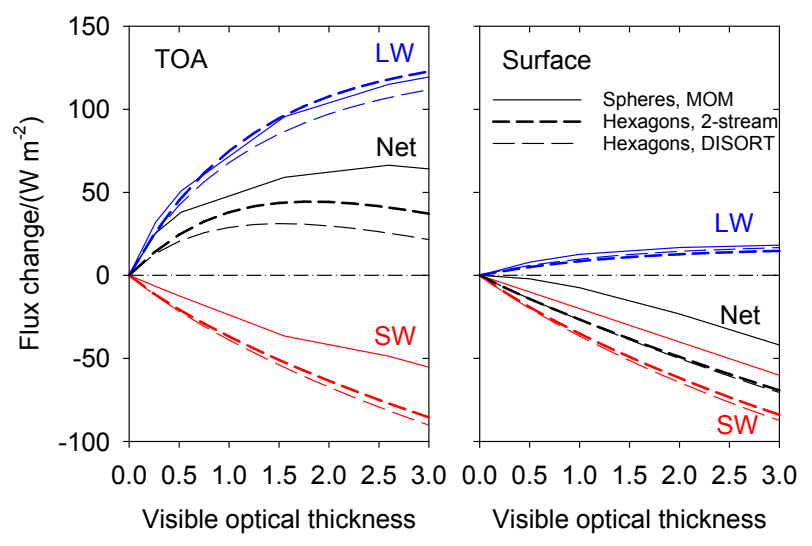

Figure 2. Daily-mean cloud radiative effects from a homogeneous contrail layer at 10 to $11 \mathrm{~km}$ altitude versus $550 \mathrm{~nm}$ optical thickness. The contrail cirrus is assumed to be composed of spheres (Meerkötter et al., 1999) or hexagons (Fu and Liou, 1993). The cloud radiative effect is the flux difference relative to the cloud-free atmosphere and computed with matrix operator method (MOM; Plass et al., 1973), two-stream and discrete ordinate (DISORT) solvers, and the Fu and Liou parameterization for molecular absorption, for daily mean at $45^{\circ} \mathrm{N}$ on 21 June, standard midlatitude summer atmosphere, over a surface with albedo 0.2 , and fixed surface temperature $(294.2 \mathrm{~K})$. Differences between the SW (LW) fluxes from the two-stream and DISORT solvers are $<6 \%(<19 \%)$.
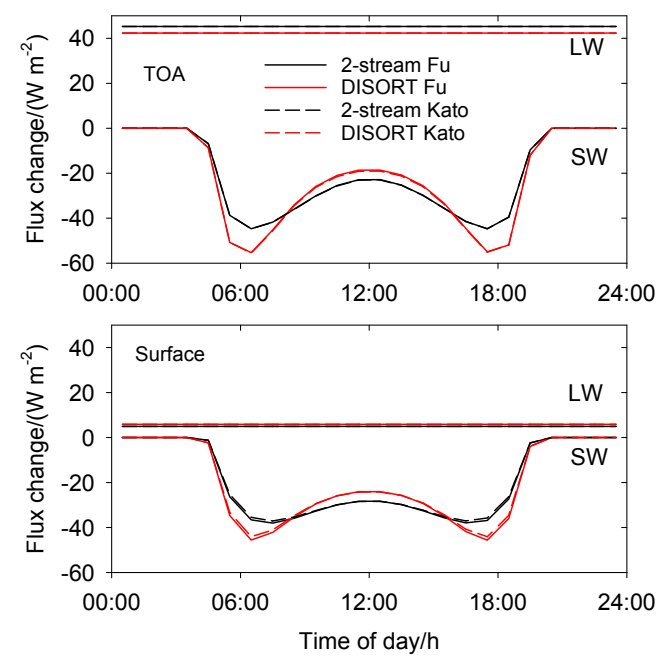

Figure 3. LW and SW flux changes versus time of day at TOA and at the surface, for two-stream and DISORT solvers, and for Fu and Liou and Kato shortwave molecular absorption parameterizations. The model parameters are the same as in Fig. $2, \tau=0.5$. The flux differences for different molecular absorption models of Fu and Kato are far smaller than between the two-stream solver and DISORT.

and for three different versions of vertical mixing: a "radiative case" with zero turbulent fluxes, a "radiative-convective case" with radiative transports and turbulent mixing in unstably stratified layers, and a "radiative-diffusive case" with 


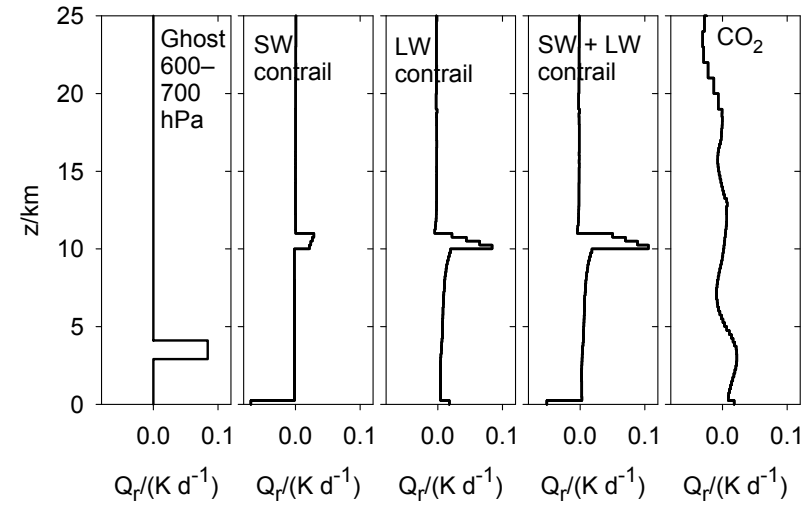

Figure 4. Initial radiative heating rates $H(t=0, z)$ versus height $z$ for a ghost forcing example, for SW, LW, and SW + LW contrail cirrus and for $\mathrm{a}_{2}$ disturbance. For plotting, the local heating rate induced by the nonzero radiative fluxes at the fixed-temperature surface is distributed over the lowest $275 \mathrm{~m}$ height (same heat capacity as $1 \mathrm{~km}$ thick cirrus layer at lower pressure).

radiative transport and mixing by constant diffusivity in the troposphere and zero diffusivity in the stratosphere. In the radiative case, the temperature change profiles are similar to vertically smoothed heating rates. Here, radiation causes the energy exchange between neighboring layers and between the air layers and the surface (Stephens, 1984; Goody and Yung, 1989). The atmosphere and the surface also emit energy directly to space. Even for ghost forcing at the surface, the lowest air layer gets warmer than the surface because the warm black surface emits radiation to space more efficiently in the partially transparent thermal infrared window between 8 and $13 \mu \mathrm{m}$ wavelengths while the air layer's emissivity is lower in this spectral range. In the lower stratosphere, the temperature increase required to balance the ghost forcing is far higher than in the troposphere because of lower emissivity and lower temperature. Turbulent mixing smoothes the profiles further, as expected. Because of stable stratification in the midlatitude reference atmosphere, convective mixing occurs only in the upper troposphere where the ghost heating is strong enough to cause local instability.

Figure $7 \mathrm{a}$ shows the surface temperature change $\Delta T_{\mathrm{S}}$ as a function of the height of the heated layer. As expected, $\Delta T_{\mathrm{S}}$ is maximum for ghost forcing directly at the surface, $\Delta T_{\mathrm{S}}=0.37 \mathrm{~K}$. Above the surface, $\Delta T_{\mathrm{s}}$ decreases with the height of the heated layer. So, the ghost forcing efficiency in heating the surface by radiation transfer decreases with layer height. For diffusive mixing, $\Delta T_{\mathrm{S}}$ is smaller $(0.26 \mathrm{~K})$ and stays close to constant within the whole troposphere. For comparison, Hansen et al. (1997a) (their Table 4 and Fig. 8a) use a coarse-resolution global circulation model and report a vertically nearly constant $\Delta T_{\mathrm{S}}$ for fixed clouds, with $\Delta T_{\mathrm{s}}=0.29 \mathrm{~K}$ when normalized to the same forcing. Apparently their model simulated strong vertical mixing. Small dif-

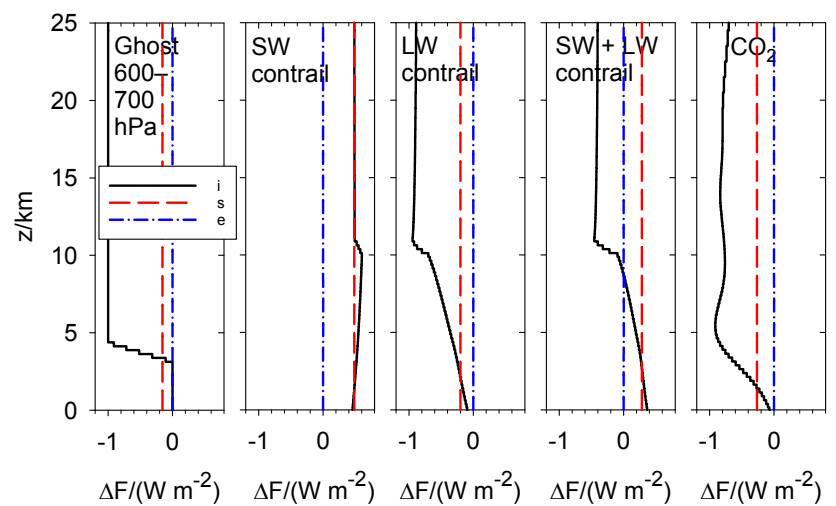

Figure 5. Initial and final radiative flux changes $\Delta F$ versus height $z$ as induced by a disturbance from added ghost heating, SW, LW, and $\mathrm{SW}+\mathrm{LW}$ contrail cirrus, and $10 \%$ increased $\mathrm{CO}_{2}$, in the panels from left to right. Black full lines (i): instantaneous flux; red dashed line (s): adjusted to constant surface temperature; blue dashdotted line (e): equilibrium over adiabatic surface. The fluxes, $F$, are positive if upwards.
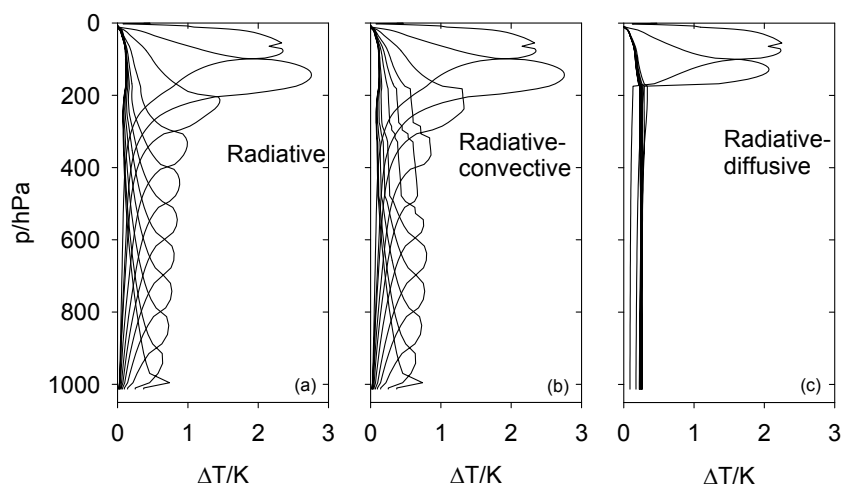

Figure 6. Temperature response versus pressure altitude for layer heating (ghost forcing) with $1 \mathrm{~W} \mathrm{~m}^{-2}$ in 10 subsequent $100 \mathrm{hPa}$ pressure layers and above an adiabatic surface. Left: the "radiative case" with zero turbulent fluxes; middle: the "radiative-convective case" with convective adjustment in addition to radiative energy transport; right: the "radiative-diffusive case" with diffusive mixing ( $\kappa=100 \mathrm{~m}^{2} \mathrm{~s}^{-1}$ in the troposphere, 0 in the stratosphere) in addition to radiative energy transport.

ferences were to be expected because of, e.g., different atmospheres.

Figure $7 \mathrm{c}$ shows the thermal relaxation timescale $t_{\mathrm{R}}=$ $\Delta T / H$ (in units of days) computed from the steady-state layer-mean temperature change $\Delta T$ in the heated layers at various levels and the corresponding heating rate $H$. For the radiative case, $t_{\mathrm{R}}$ is 0.45 days near the surface (and smaller for thinner surface air layers), 6.6 days in the first $100 \mathrm{hPa}$ layer, 11 days in the upper troposphere, 30 days in the tropopause region between 100 and $200 \mathrm{hPa}$, and 23 days in the top $100 \mathrm{hPa}$ layer. For layers with $200 \mathrm{hPa}$ depth instead of $100 \mathrm{hPa}$, the heating response is smoother, causing 

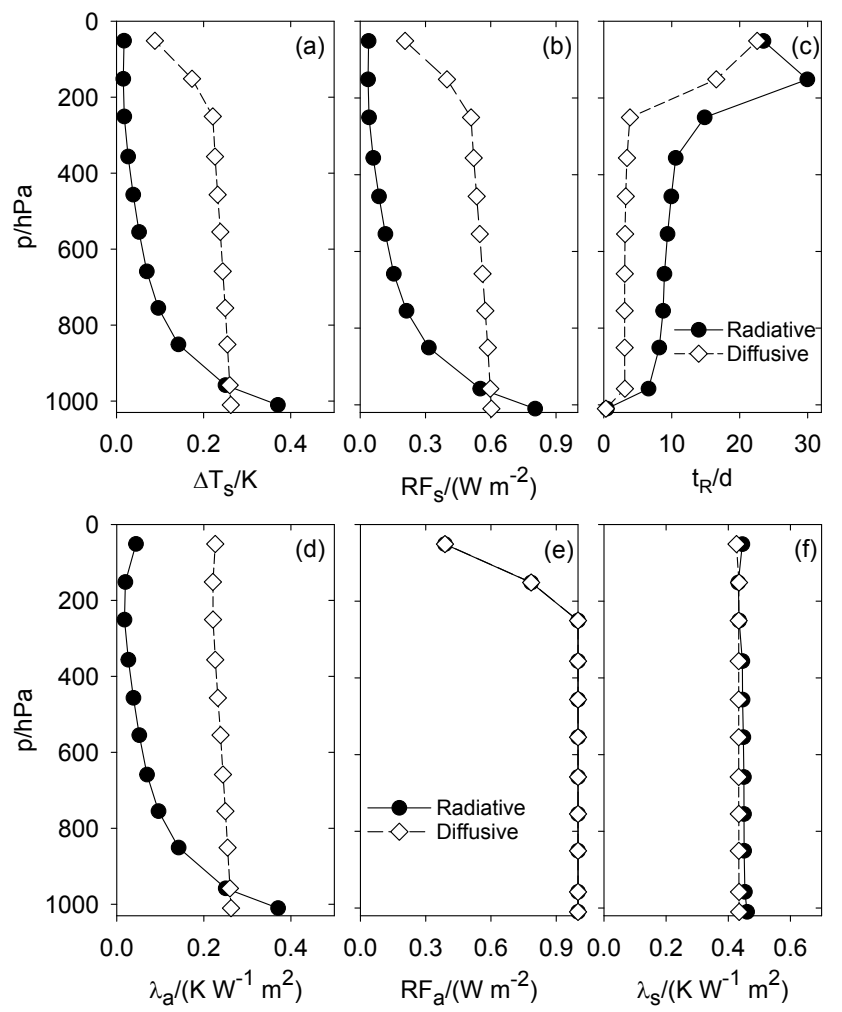

Figure 7. (a) Temperature change at the surface for layer heating versus the layer pressure height. The ghost forcing corresponds to an $\mathrm{RF}_{\mathrm{i}}$ of $1 \mathrm{~W} \mathrm{~m}^{-2}$ at TOA. Black symbols with full line: radiative case; white symbols with dashed line: radiative-diffusive case. (b) Corresponding $\mathrm{RF}_{\mathrm{S}}$ values for fixed $T_{\mathrm{S}}$. (c) Relaxation timescales $t_{\mathrm{R}}=\Delta T_{\text {layer }} / H$. (d) Climate sensitivity parameter $\lambda_{\mathrm{a}}=$ $\Delta T_{\mathrm{S}} / \mathrm{RF}_{\mathrm{a}}$ based on stratosphere-adjusted $\mathrm{RF}_{\mathrm{a}}$; (e) $\mathrm{RF}_{\mathrm{a}}$; (f) climate sensitivity parameter $\lambda_{\mathrm{S}}=\Delta T_{\mathrm{S}} / \mathrm{RF}_{\mathrm{S}}$ based on effective $\mathrm{RF}_{\mathrm{S}}$.

about $50 \%$ larger timescales. Hence, as expected (Goody and Yung, 1989), the sensitivity to layer depth is less than linear. Radiation causes nonlocal energy transfer, different from diffusion processes for which the sensitivity to layer depth would be quadratic. The smaller timescales in the lowest layers are again a consequence of effective radiation emission via the surface. The relaxation times in the highest layer are lower than in the second highest layer because of stronger heat loss from the middle atmosphere to space (Zhu, 1993). As expected, mixing reduces the layer warming and the related timescales. Mixing in the troposphere also reduces stratospheric timescales by enhanced heat exchange with and within the troposphere and enhanced heat loss from the surface to space. With the diffusive mixing, the thermal relaxation times for heating in the troposphere approach a low and vertically constant value of about 3.2 days. For an atmosphere in which the adiabatic surface is replaced by a constant-temperature surface, the timescale $t_{\mathrm{R}}$ is zero at the surface; $t_{\mathrm{R}}$ reduces by $34 \%$ in the first $100 \mathrm{hPa}$ layer and by $12 \%$ in the second layer, with smaller changes at higher lev- els. In the diffusive case, because of combined transport by radiation and mixing, heat has a lower residence time than a passive tracer with similar source location and constant concentration at the Earth's surface. For comparison, passive aircraft emissions may well exceed an atmospheric residence time of 1 month when emitted into the lower stratosphere (Forster et al., 2003) but reach ground within less than about a week when emitted in the mid troposphere (Danilin et al., 1998).

Figure $7 \mathrm{~b}$ and e show the adjusted and effective $\mathrm{RF}_{\mathrm{a}}$ and $R F_{s}$ versus the height of the heated layer. $R F_{a}$ equals $R F_{i}=$ $1 \mathrm{~W} \mathrm{~m}^{-2}$, regardless of the layer height as long as the heated layer is fully below the tropopause (Hansen et al., 1997a). The ratio $\mathrm{RF}_{\mathrm{s}} / \mathrm{RF}_{\mathrm{i}}$ measures the fraction of heat that warms the compartment below the surface after the air temperature has adjusted to the induced heat disturbance. $R F_{s} / R F_{i}$ is largest for heating near the surface: 0.80 without diffusive mixing. Hence, after fast adjustment, when the troposphere has reached its higher steady-state temperature, about $80 \%$ of the input heat heats the compartment below the Earth's surface (e.g., ocean) and $20 \%$ of the heat radiates out to space. For heating near the tropopause, about $95 \%$ of the heat leaves to space. For strong vertical mixing, $\mathrm{RF}_{\mathrm{s}} / \mathrm{RF}_{\mathrm{i}}$ is about $60 \%$ and vertically nearly uniform. Hence, even with strong mixing, $\sim 40 \%$ of the ghost heating radiates directly to space.

Finally, Fig. $7 \mathrm{~d}$ and $\mathrm{f}$ show $\lambda_{\mathrm{a}}$ and $\lambda_{\mathrm{s}}$, the sensitivity parameters of $\Delta T_{\mathrm{S}}$ to $\mathrm{RF}_{\mathrm{a}}$ and $\mathrm{RF}_{\mathrm{s}}$. For heating at the surface, $\lambda_{\mathrm{a}}=0.37 \mathrm{~K} \mathrm{~W}^{-1} \mathrm{~m}^{2}$. This value is larger than the planetary sensitivity $\left(0.27 \mathrm{~K} \mathrm{~W}^{-1} \mathrm{~m}^{2}\right.$, without feedbacks) because the atmosphere reduces heat losses from the surface. Without diffusive mixing, the values of $\lambda_{\mathrm{a}}$ decrease strongly with height, because heating at higher levels is less efficient in radiative surface warming. With diffusive mixing, $\lambda_{\mathrm{a}}$ approaches a constant because the heating is distributed quickly over the troposphere regardless of the layer height. In contrast, the value of $\lambda_{\mathrm{s}}$ is close to a constant because $\mathrm{RF}_{\mathrm{s}}$ already accounts for the fast temperature profile adjustment. Therefore, as expected (Shine et al., 2003), $\mathrm{RF}_{\mathrm{s}}$ is a better measure for surface temperature change than $\mathrm{RF}_{\mathrm{a}}$.

Since ghost forcings change the temperature, they affect $\mathrm{LW}$ radiation. The changes depend solely on the temperature profile of the reference atmosphere and the infrared optical properties of the atmosphere and the surface. The solar irradiance is unimportant for fixed dynamical heating. The model response is quasi-linear in the magnitude of the disturbances for fixed mixing properties as long as the temperature changes are small compared to absolute temperature. To illustrate the quasi-linearity, we tested the model with ghost forcing increased from 1 to $4 \mathrm{~W} \mathrm{~m}^{-2}$. The values of $t_{\mathrm{R}}$ for ghost forcing at the surface are reduced by up to $0.5-5.7 \%$ for this change, for the three cases, with largest changes for the radiative-convective case. For $\lambda_{s}$, the changes range from 0.6 to $1.2 \%$. Further tests have shown that the basic altitude 
dependence in the sensitivity to ghost forcing also exists for zero dynamical heating.

We also applied the model for atmospheres with an additional cirrus layer in the upper troposphere, with increased humidity, with increased absolute humidity keeping the relative humidity constant, with increased $\mathrm{CO}_{2}$, and for other standard atmospheres. All these changes cause changed $t_{\mathrm{R}}$, $\mathrm{RF}_{\mathrm{S}}$, and temperature sensitivity $\lambda_{\mathrm{s}}$ values. Clouds of sufficient optical depth above the heated layers reduce the heat loss to space notably. A uniformly higher humidity in the atmosphere enhances the infrared layer emissivity, causing stronger local cooling from a ghost layer to space; it also increases the optical thickness between the layer and the surface, reducing surface temperature changes. This is no contradiction to the fact that increases in stratospheric water vapor (and $\mathrm{CO}_{2}$ ) act to cool the stratosphere but to warm the troposphere (Manabe and Wetherald, 1967; Shine and Sinha, 1991; Solomon et al., 2010). In the more humid tropics with higher and colder tropopause, the relaxation timescales are about $20 \%$ smaller than at midlatitudes. The response to changes for fixed relative humidity helps to explain climate change feedbacks (Manabe and Wetherald, 1967) but requires a more extensive model to be realistic. For an atmosphere with doubled $\mathrm{CO}_{2}$, the changes are qualitatively similar to increased $\mathrm{H}_{2} \mathrm{O}$, but of smaller magnitude. High and thick clouds are far more efficient in changing the radiative relaxation timescales in the troposphere than added $\mathrm{H}_{2} \mathrm{O}$ or $\mathrm{CO}_{2}$.

\subsection{Contrail cirrus in comparison to $\mathrm{CO}_{2}$}

In this section we consider the temperature changes induced by a contrail cirrus example, a thin homogenous cirrus layer at 10 to $11 \mathrm{~km}$ altitude, with $3 \%$ coverage (typical for midlatitude contrails) in an otherwise fixed Earth-atmosphere system. The ice water content of the cirrus is adjusted to an optical thickness $\tau=0.3$ at $550 \mathrm{~nm}$ wavelength, and the effective radius of the hexagonal ice particles in this model is set to $20 \mu \mathrm{m}$, typical for aged contrails (Minnis et al., 2013; Schumann et al., 2017). At TOA, the net instantaneous RF is positive while the net surface $\mathrm{RF}_{\mathrm{i}}$ is negative, consistent with earlier results (see Fig. 2). For comparison, we also consider a $10 \%$ increase in $\mathrm{CO}_{2}\left(360\right.$ to $\left.396 \mu \mathrm{mol} \mathrm{mol}^{-1}\right)$ in the same model. Figures 4 and 5 show the instantaneous radiative flux changes and the corresponding heating rates for added SW, LW, and "normal" (SW + LW) contrail cirrus and for increased $\mathrm{CO}_{2}$. Figure 8 shows the steady-state temperature response to the radiative disturbance for the three cirrus cases and $\mathrm{CO}_{2}$.

For contrail cirrus (Fig. 8), we see strongly different temperature responses in the net, $\mathrm{SW}$, and $\mathrm{LW}$ versions. The $\mathrm{SW}$ contrail causes a slight warming inside the cirrus layer by solar radiation absorption (Stackhouse and Stephens, 1991). The main SW effect is a cooling of the lower troposphere, culminating at the Earth's surface. The LW contrail enhances
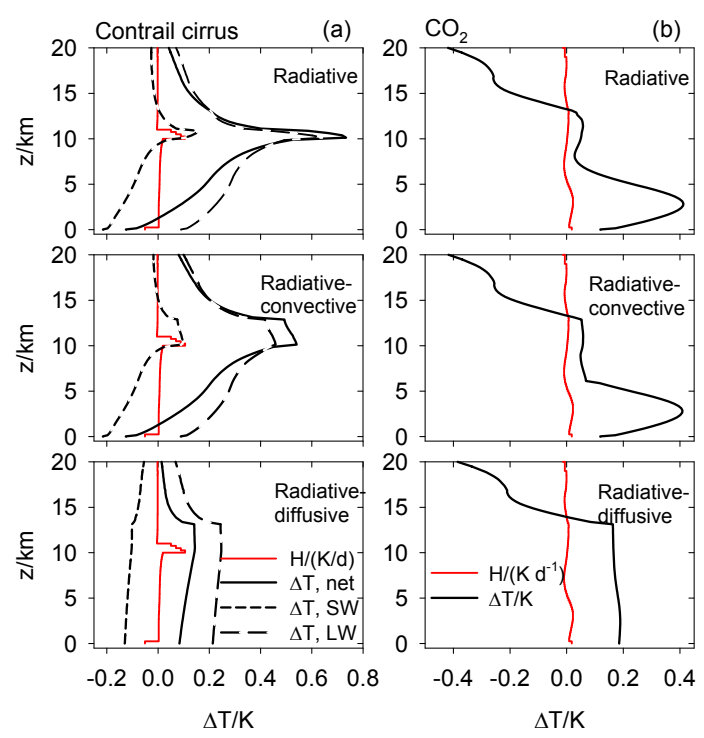

Figure 8. Temperature change $\Delta T$ in $\mathrm{K}$ versus altitude $z$ in $\mathrm{km}$ (black lines) for disturbances by $\mathrm{CO}_{2}$ (right) and by $\mathrm{SW}$, $\mathrm{LW}$, and combined LW + SW contrail cirrus (left) in steady state for the radiative, radiative-convective, and radiative-diffusive cases. The red curves show the net $(\mathrm{LW}+\mathrm{SW})$ initial instantaneous heating ratings in $\mathrm{Kday}^{-1}$.

infrared absorption inside the layer and slightly warms the troposphere below by emission from the contrail. In addition, the LW contrail enhances the radiation energy budget at the Earth's surface, causing a slight warming, but the SW cooling dominates. In the radiative case, the temperature change is positive in the upper troposphere and negative near the surface. Convective mixing occurs in this atmosphere, with fixed dynamical heating, only in the upper troposphere where the contrail heating causes unstable stratification. The diffusive mixing distributes the heat nearly uniformly over the troposphere. Without such mixing, the heat induced radiatively by the contrail in the upper troposphere is inefficient in heating the surface.

The $\mathrm{CO}_{2}$ case shows tropospheric warming as expected (Ramanathan and Coakley, 1978; Manabe and Stouffer, 1980; Ogura et al., 2014). The initial heating, mainly from $\mathrm{LW}$ radiation, is positive but small $\left(<0.022 \mathrm{Kday}^{-1}\right)$ in the troposphere and negative in the upper stratosphere with far larger magnitude $\left(-0.6 \mathrm{~K} \mathrm{day}^{-1}\right.$ at $\left.60 \mathrm{~km}\right)$. Enhanced $\mathrm{CO}_{2}$ not only heats the troposphere but also increases the downwelling LW flux reaching the surface. For the given atmospheres and disturbances, convective adjustment occurs only in the middle and in the upper troposphere; the other parts remain stably stratified. The literature shows a range of results for $\mathrm{CO}_{2}$-induced heating rates (Collins et al., 2006; Dietmüller et al., 2016). The larger global mean upper-tropospheric temperature response in climate models (Hansen et al., 1997a) results from amplification by various feedbacks not included in this model. Global models often 
Table 1. Radiative Forcing $(\mathrm{RF})^{*}$, surface temperature change $\Delta T_{\mathrm{S}}$, sensitivity parameters $\lambda$ and efficacies $e$ relative to adjusted and effective $\mathrm{RF}_{\mathrm{a}}$ and $\mathrm{RF}_{\mathrm{s}}$, for contrail cirrus and $\mathrm{CO}_{2}$ for the given model. The first four rows are the radiative cases with zero turbulent fluxes, the last four rows apply for the radiative-diffusive cases. The instantaneous and adjusted RF values are the same for both cases. Negative $\lambda$ and $e$ values are considered ill-conditioned because highly sensitive to small changes in forcing and mixing contributions.

\begin{tabular}{|c|c|c|c|c|c|c|c|c|c|c|c|}
\hline & $\begin{array}{r}\mathrm{RF}_{\mathrm{i}} \\
\mathrm{W} \mathrm{m}^{-2}\end{array}$ & $\begin{array}{r}\mathrm{RF}_{\mathrm{i}, \mathrm{TOA}} \\
\mathrm{W} \mathrm{m}^{-2}\end{array}$ & $\begin{array}{r}\mathrm{RF}_{\mathrm{i}, \mathrm{SUR}} \\
\mathrm{W} \mathrm{m}^{-2}\end{array}$ & $\begin{array}{r}\mathrm{RF}_{\mathrm{a}} \\
\mathrm{W} \mathrm{m}^{-2}\end{array}$ & 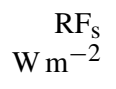 & $\begin{array}{r}\Delta T_{\mathrm{S}} \\
\mathrm{K}\end{array}$ & $\begin{array}{r}\lambda_{\mathrm{a}} \\
\mathrm{K} \mathrm{W}^{-1} \mathrm{~m}^{2}\end{array}$ & $\begin{array}{r}\lambda_{\mathrm{s}} \\
\mathrm{K} \mathrm{W}^{-1} \mathrm{~m}^{2}\end{array}$ & $\begin{array}{r}e_{\mathrm{a}} \\
1\end{array}$ & $\begin{array}{r}e_{\mathrm{S}} \\
1\end{array}$ & $\mathrm{RF}_{\mathrm{S}} / \mathrm{RF}_{\mathrm{i}, \mathrm{TOA}}$ \\
\hline \multicolumn{12}{|c|}{ Radiative case } \\
\hline $\mathrm{CO}_{2}$ & 0.83 & 0.41 & 0.07 & 0.72 & 0.26 & 0.12 & 0.16 & 0.45 & 1 & 1 & 0.64 \\
\hline SW cirrus & -0.49 & -0.48 & -0.46 & -0.49 & -0.48 & -0.22 & 0.44 & 0.44 & 2.69 & 0.99 & 1.00 \\
\hline LW cirrus & 0.92 & 0.88 & 0.09 & 0.90 & 0.20 & 0.09 & 0.10 & 0.45 & 0.60 & 0.99 & 0.23 \\
\hline Cirrus & 0.43 & 0.40 & -0.37 & 0.42 & -0.28 & -0.13 & -0.30 & 0.44 & -1.83 & 0.98 & -0.70 \\
\hline \multicolumn{12}{|c|}{ Radiative-diffusive case } \\
\hline $\mathrm{CO}_{2}$ & 0.83 & 0.41 & 0.07 & 0.72 & 0.70 & 0.19 & 0.26 & 0.26 & 1 & 1 & 1.70 \\
\hline SW cirrus & -0.49 & -0.48 & -0.46 & -0.49 & -0.49 & -0.13 & 0.27 & 0.26 & 1.04 & 1.00 & 1.03 \\
\hline LW cirrus & 0.92 & 0.88 & 0.09 & 0.90 & 0.81 & 0.21 & 0.24 & 0.26 & 0.92 & 1.00 & 0.92 \\
\hline Cirrus & 0.43 & 0.40 & -0.37 & 0.42 & 0.32 & 0.08 & 0.20 & 0.26 & 0.79 & 1.00 & 0.79 \\
\hline
\end{tabular}

* Index i for instantaneous values at tropopause (TP), top of atmosphere (TOA), and surface (SUR); a for adjusted at TP; and s for effective at TP.

show a rather smooth profile of temperature increase in the troposphere, likely because of strong mixing. At high latitudes, reduced vertical mixing under stably stratified conditions, besides sea ice albedo changes, is known to cause enhanced $\mathrm{LW}$ warming at the surface from increased $\mathrm{CO}_{2}$ (Wetherald and Manabe, 1975).

Table 1 lists the values for $\mathrm{RF}_{\mathrm{i}}$ (at TP, TOA, and surface), $\mathrm{RF}_{\mathrm{a}}$, and $\mathrm{RF}_{\mathrm{s}}$ at the TP, $\Delta T_{\mathrm{s}}$, and related $\lambda_{\mathrm{a}}, \lambda_{\mathrm{s}}$, and efficacy values $\left(e_{\mathrm{a}}, e_{\mathrm{s}}\right)$, with respect to the $\mathrm{CO}_{2}$ disturbance, for the radiative and diffusive cases. The instantaneous and stratospheric adjusted values apply to fixed troposphere and are, hence, independent of tropospheric mixing. The results for the radiative-convective case are close to the radiative case and therefore not shown.

For $\mathrm{CO}_{2}, \mathrm{RF}_{\mathrm{i}}$ is positive throughout the atmosphere. $\mathrm{RF}_{\mathrm{a}}$ at the tropopause is in between the $\mathrm{RF}_{\mathrm{i}}$ values at TOA and at the tropopause, consistent with earlier results (Stuber et al., 2001; Dietmüller et al., 2016). The effective $\mathrm{RF}_{\mathrm{s}}$ for fixed climate system is in between the $\mathrm{RF}_{\mathrm{i}}$ values at the tropopause and at the surface.

For contrail cirrus, Table 1 shows that the net $\mathrm{RF}_{\mathrm{a}}$ is about half the value of the LW contribution but still positive in spite of SW cooling. The value of $\mathrm{RF}_{\mathrm{a}}$ is not much different from $R F_{i}$, consistent with Dietmüller et al. (2016). The $R_{F}$ values differ strongly from $\mathrm{RF}_{\mathrm{a}}$, even with a different sign in the radiative case without diffusive mixing. For SW and LW cirrus separately, the ratio $R F_{s} / R_{i}$,TOA increases strongly for diffusive mixing, e.g., from 0.23 to 0.92 for LW cirrus. At steady state, more and more of the heat induced radiatively by the cirrus reaches the surface and less leaves to space for increased mixing. The temperature sensitivity $\lambda_{\mathrm{s}}$ is about $40 \%$ smaller with the mixing. Surface heating (or cooling) is more efficient in heating the underlying compartment (larger $\mathrm{RF}_{\mathrm{s}} / \mathrm{RF}_{\mathrm{i}}$ ) than upper-tropospheric heating. For the $\mathrm{LW}+\mathrm{SW}$ contrail, the SW and $\mathrm{LW}$ results for RF and temperature add linearly. However, the sensitivities and efficacies change nonlinearly because they are ratios of RF and $\Delta T_{\mathrm{S}}$ values. Based on $\mathrm{RF}_{\mathrm{a}}$, the efficacy of $\mathrm{SW}$ contrail cirrus is larger than for LW contrail cirrus. Hence, efficacies derived from stratosphere-adjusted RF depend on the heating profiles and on the mixing in the troposphere. Based on $\mathrm{RF}_{\mathrm{s}}$, the efficacies for SW and LW contrail cirrus are close to unity. They are all close to 1 , because the cloud and the $\mathrm{CO}_{2}$ changes considered are small disturbances of the same climate system and the modeled climate systems remain similar even after fast adjustments in these model cases.

The thin contrail cirrus barely changes the thermal relaxation properties of the atmosphere. It would require a contrail cirrus with optical depth of the order of 1 and $100 \%$ cover to cause strong changes of the heat losses to space. Hence, the insight gained for ghost forcing, consistent with Hansen et al. (1997a), helps to understand the temperature changes induced by radiative heating from contrails. For weak mixing, $\Delta T_{\mathrm{S}}$ is highly sensitive to the altitude in which the cirrus heating is induced. Also the dependence of $\lambda$ on mixing and the usefulness of effective $\mathrm{RF}_{\mathrm{s}}$ to estimate $\Delta T_{\mathrm{s}}$ with nearly constant $\lambda_{\mathrm{s}}$ found for ghost forcing apply similarly for cirrus. Similar efficacies can be expected only for similar atmospheres and sufficient vertical mixing. In all cases, we find that the effective $\mathrm{RF}_{\mathrm{s}}$ is in between $\mathrm{RF}_{\mathrm{i}}$ at the tropopause and at the surface. This finding may be helpful for estimating $\mathrm{RF}_{\mathrm{s}}$ for given instantaneous RF.

Different from ghost forcing, the contrails change the optical properties not only in the infrared but also in the solar range. The effects of the contrails are, of course, sensitive to surface albedo and SZA, which were irrelevant for ghost forcing. However, the model still behaves quasi-linearly. An increase of contrail coverage, e.g., from 3 to $12 \%$, changes 
the efficacies by $0.38,3.87$, and $-2.76 \%$ for SW, LW, and $\mathrm{SW}+\mathrm{LW}$ contrails in the radiative case and by smaller values for the two cases with mixing. Some of the cases were recomputed with DISTUF instead of the more efficient twostream solver. For $\mathrm{CO}_{2}$ and $\mathrm{SW}+\mathrm{LW}$ contrail cirrus, the values in Table 1 differ by $<8 \%$ in magnitude between the two solvers.

Ponater et al. (2005) studied contrail climate sensitivity with a global circulation model. They show a plot of the zonal mean vertical cross section of annual mean temperature response in the equilibrium climate which shows that the contrail-induced warming is largest in the upper troposphere and limited to the latitude band in which contrails formed. The maximum in the upper troposphere cannot be explained by local release of latent heat, because the amount of water condensing during cloud formation at those low temperature levels is small. The pattern with enhanced temperature for contrails is more pronounced than for a similar $\mathrm{CO}_{2}$ disturbance simulation (see Fig. 1 of Ponater et al., 2006b). Hence, the mixing was likely not strong enough to disperse the contrail-induced radiative heating uniformly over the troposphere. The different efficacies found by Rap et al. (2010a) and by Ponater et al. (2005) may be caused by different vertical mixing in the different models, in addition to different ratios of SW to LW RF magnitudes and different feedbacks.

Figure 9 illustrates the timescales of temperature relaxation inside the atmosphere for a non-steady case. Here we show temperature profiles as a function of time starting from steady state for the given contrail cirrus over an adiabatic surface, e.g., over land, after the contrail is suddenly taken away. The times needed to reach half the initial values, derived from plots of the results versus time, are $0.8,8$, and 50 days for the temperature at the surface, on average in the contrail layer, and in the troposphere, respectively, for the radiative case. The mean tropospheric halving time is 12 days for the radiative-diffusive case. As expected from the ghost forcing results, the temperature change returns to zero most rapidly at the surface; the temperature within the contrail layer also returns to tropospheric mean values quickly because of the relatively small geometrical contrail layer depth, while the troposphere itself needs nearly 2 months to reach half its initial mean value. The larger troposphere value is a consequence of its larger thickness. For constant surface temperature and the diffusive mixing, the troposphere reaches half its initial value after 2.7 days. Of course, thermal inertia of an ocean would increase heat residence times to many years (Hansen et al., 1985). The example illustrates quick losses of energy by radiation to space, which gets enhanced by mixing within the troposphere.

\section{Summary, implications, and conclusions}

The surface temperature sensitivity to small climate disturbances has been investigated in an idealized climate model
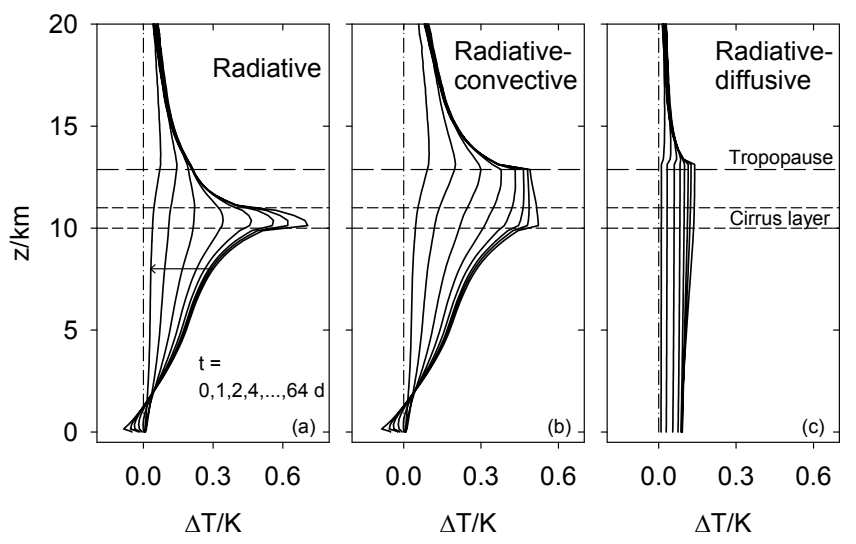

Figure 9. Decay of an initially steady-state contrail-cirrus-induced temperature increase, at times $0,1,2,4, \ldots, 64$ days after the contrail cirrus ceased, in three panels for the radiative, radiative-convective, and radiative-diffusive cases. Tropopause and contrail layer heights are indicated by dashed lines.

without feedbacks except by temperature changes and lapserate-dependent convection. The model is a one-dimensional representation of the midlatitude summer atmosphere with constant insolation. Fixed dynamical heating is imposed to study small disturbances of an undisturbed atmosphere in steady state. The boundary conditions prescribe either fixed surface temperature or zero heat flux through the surface. The fixed-surface-temperature case is used to simulate fast adjustment processes; it provides the effective RF estimate. The zero-heat-flux case simulates an atmosphere in thermal equilibrium with the compartment below the surface. Disturbances considered are layer heating (ghost forcing), a prescribed contrail cirrus layer, and a $10 \%$ increase of $\mathrm{CO}_{2}$ mixing ratio. Radiative fluxes are computed with an efficient two-stream solver from libRadtran. Diffusive fluxes are driven by the potential temperature gradient. The diffusivity is set either constant or lapse-rate dependent to simulate vertical diffusive mixing, e.g., from large-scale eddies, or convective adjustment in unstable layers of the atmosphere. The model response is quasi-linear in the magnitude of the disturbances for fixed mixing properties but nonlinear with lapserate-dependent convective adjustment. From the model results, the ratio of layer-mean temperature changes to heating rates is used to characterize the timescales for radiative relaxation. Model results for various boundary conditions are used to compute instantaneous, stratosphere-adjusted, and effective $R F$, i.e., $R F_{i}, R F_{a}$, and $R F_{s}$.

The model results provide thermal relaxation timescales of the order of hours near the surface, of about 1 to 2 weeks in the upper troposphere and of the order of a month in the lower stratosphere. After fast adjustment, $\mathrm{RF}_{\mathrm{s}}$ is nonzero and smaller in magnitude than $\mathrm{RF}_{\mathrm{i}}$. Final thermal equilibrium with an ocean below the surface would be reached far later, after many years to centuries. This final state is 
simulated with the zero-flux boundary condition. The ratio $\mathrm{RF}_{\mathrm{S}} / \mathrm{RF}_{\mathrm{i}, \mathrm{TOA}}$ measures the fraction of the instantaneous energy flux change at TOA available after fast adjustments for long-term heating of the compartment below the surface. The ratio $\mathrm{RF}_{\mathrm{s}} / \mathrm{RF}_{\mathrm{i}}$ depends on the height at which the disturbance induces radiative heating. For zero turbulent mixing, $\mathrm{RF}_{\mathrm{s}} / \mathrm{RF}_{\mathrm{i}}$ decreases from large values $(80 \%$ in the case simulated) for heating directly at the surface to small values $(<5 \%)$ above the tropopause. For the diffusive vertical mixing in the troposphere, the ratio $\mathrm{RF}_{\mathrm{s}} / \mathrm{RF}_{\mathrm{i}}$ approaches a constant of the order of $60 \%$. Hence, a large fraction (about $40 \%$ ) of the initial energy flux disturbance radiates to space and cannot heat the compartment below the surface. The temperature sensitivity varies with layer height if defined relative to $\mathrm{RF}_{\mathrm{i}}$ but is constant relative to $\mathrm{RF}_{\mathrm{s}} . \mathrm{RF}_{\mathrm{s}}$ controls the transient heating rate of the compartment below the surface.

The contrail layer introduces a positive instantaneous RF at TOA in the LW and a negative RF in the SW range with a positive net RF. The heating rate profiles in the LW and SW ranges are different with larger magnitude near the surface for SW than for LW flux changes. At the surface, the net RF is negative. As a consequence, the temperature sensitivities $\lambda_{\mathrm{a}}$ differ between the LW and SW forcing parts and change depending on the degree of mixing. For zero mixing, the surface energy budget with SW cooling may dominate the LW warming at the surface. Hence, in such an extreme case, the temperature sensitivity could be negative. In the analyzed case without mixing, the LW and SW $\lambda_{\mathrm{a}}$ values differ by a factor of 4.4 but only by $10 \%$ with diffusive mixing.

Taking the temperature sensitivity to the $\mathrm{CO}_{2}$ disturbance in the same atmosphere for reference, we find that the contrail efficacies based on $\mathrm{RF}_{\mathrm{a}}$ are near 0.8 while those based on $\mathrm{RF}_{\mathrm{s}}$ are near 1 . The temperature sensitivity for the sum of SW and LW RF is the ratio of differences of large opposing values and, hence, sensitive to minor system changes. So, for contrails with large and nearly canceling LW and SW effects, no simple relationship between radiative forcing and temperature change may exist. The findings may apply also for other disturbances.

It is important to keep in mind that the results presented in this study are from a conceptual model. The results are model and case dependent. The fast adjustment and even more the equilibrium responses in general depend on many feedbacks to the temperature-mediated climate system changes, not included in this study. Any change in the model setup, the reference atmosphere, or the nature and magnitude of the disturbances would change the results at least quantitatively. Hence, though our study shows the principle importance of mixing for climate sensitivity to contrails, we cannot say how important mixing is for real-world cases quantitatively. Ultimately, this requires careful simulations with a comprehensive climate model.

The results of one climate model study (Ponater et al., 2005) support the conclusion that the mixing of contrailinduced warming may be indeed weak and insufficient to mix the heat over the troposphere uniformly. Differences between the efficacy estimates from various studies may partly be caused by different mixing rates in the models used. Future studies should document the mean radiative, adjective, and turbulent energy fluxes, including the TOA and surface energy budgets, to allow for analysis of the relative importance of various energy transport mechanisms for climate sensitivity.

It may be of interest whether a correlation between contrails and atmospheric mixing conditions exists. Contrailinduced heating in the upper troposphere during calm weather may contribute less to surface warming than the same forcing in a strongly mixing weather situation. Shorter timescales of SW-induced temperature changes near the surface may lead to a dominance of SW surface cooling relative to LW warming regionally where contrails form, while remaining LW warming may dominate after advection downstream at larger distances. The importance of advection of heat induced by contrail warming has been noted previously (Ponater et al., 1996; Rind et al., 2000), as well as for other disturbances (Shindell et al., 2010), but the potential for different radiative warming and cooling effects at different altitudes has not yet been discussed.

These findings may have implications for the assessment of the climate impact of aviation by contrails. So far, equilibrium warming from contrails is computed using estimates of $\mathrm{RF}\left(\mathrm{RF}_{\mathrm{i}}\right.$ or $\left.\mathrm{RF}_{\mathrm{a}}\right)$ together with a $\mathrm{CO}_{2}$ climate sensitivity corrected by a contrail efficacy (Ponater et al., 2006a; D. S. Lee et al., 2009; Frömming et al., 2012). Our study suggests that the efficacy should be different for SW and LW forcings. This may be important for comparison of the climate impact of different contrail cases, e.g., for different diurnal traffic cycles or different route settings.

This study provides further insight into known limitations of the RF model approach. Hence, better approaches are needed. A suggestion for an alternative to the RF concept, based on a new temperature forcing concept, will be described in a follow-up paper to this study.

Data availability. No specific data are used except as cited.

Competing interests. The authors declare that they have no conflict of interest.

Acknowledgements. Stimulating discussions with Klaus Gierens, Michael Ponater, and Robert Sausen are gratefully acknowledged. Discussions with Markus Rapp, William B. Rossow, Keith Shine, Thomas Spengler, Björn Stevens, Manfred Wendisch, and Sebastian Schmidt helped to sharpen the arguments. An invitation by Z. Jonny Luo to the Bill Rossow's retirement symposium in New York in June 2017 triggered part of this research. We thank the reviewers for several comments which lead to improvements of the paper. 
The article processing charges for this open-access

publication were covered by a Research

Centre of the Helmholtz Association.

Edited by: Johannes Quaas

Reviewed by: two anonymous referees

\section{References}

Ackerman, T. P., Liou, K. N., Valero, F. P. J., and Pfister, L.: Heating rates in tropical anvils, J. Atmos. Sci., 45, 1606-1623, 1988.

Allan, R. P.: Combining satellite data and models to estimate cloud radiative effect at the surface and in the atmosphere, Meteorol. Appl., 18, 324-333, https://doi.org/10.1002/met.285, 2011.

Anderson, G., Clough, S., Kneizys, F., Chetwynd, J., and Shettle, E.: AFGL atmospheric constituent profiles $(0-120 \mathrm{~km})$, Tech. Rep. AFGL-TR-86-0110, Air Force Geophys. Lab., Hanscom Air Force Base, Bedford, Mass., USA, 43 pp., 1986.

Berry, E. and Mace, G. G.: Cloud properties and radiative effects of the Asian summer monsoon derived from A-Train data, J. Geophys. Res., 119, 9492-9508, https://doi.org/10.1002/2014JD021458, 2014.

Bi, L. and Yang, P.: Improved ice particle optical property simulations in the ultraviolet to far-infrared regime, J. Quant. Spectrosc. Ra., 189, 228-237, https://doi.org/10.1016/j.jqsrt.2016.12.007, 2017.

Bock, L. and Burkhardt, U.: Reassessing properties and radiative forcing of contrail cirrus using a climate model, J. Geophys. Res., 121, 9717-9736, https://doi.org/10.1002/2016JD025112, 2016.

Bony, S., Colman, R., Kattsov, V. M., Allan, R. P., Bretherton, C. S., Dufresne, J. L., Hall, A., Hallegate, S., Holland, M. M., Ingram, W., Randall, D. A., Soden, B. J., Tseloudis, G., and Webb, M. J.: How well do we understand and evaluate climate feedback processes?, J. Climate, 19, 3345-3348, https://doi.org/10.1175/JCLI3819.1, 2006.

Boucher, O., Randall, D., Artaxo, P., Bretherton, C., Feingold, G., Forster, P., Kerminen, V.-M., Kondo, Y., Liao, H., Lohmann, U., Rasch, P., Satheesh, S. K., Sherwood, S., Stevens, B., and Zhang, X. Y.: Clouds and Aerosols, in: Climate Change 2013: The Physical Science Basis, edited by: Stocker, T. F., Qin, D., Plattner, G.K., Tignor, M., Allen, S. K., Boschung, J., Nauels, A., Xia, Y., Bex, V., and Midgley, P. M., Cambridge University Press, Cambridge, UK and New York, NY, USA, 571-657, 2013.

Burkhardt, U. and Kärcher, B.: Global radiative forcing from contrail cirrus, Nat. Clim. Change, 1, 54-58, https://doi.org/10.1038/NCLIMATE1068, 2011.

Chen, C.-C. and Gettelman, A.: Simulated radiative forcing from contrails and contrail cirrus, Atmos. Chem. Phys., 13, 1252512536, https://doi.org/10.5194/acp-13-12525-2013, 2013.

Chen, T., Rossow, W. B., and Zhang, Y. C.: Radiative effects of cloud-type variations, J. Climate, 13, 264-286, 2000.

Collins, W. D., Ramaswamy, V., Schwarzkopf, M. D., Sun, Y., Portmann, R. W., Fu, Q., Casanova, S. E. B., Dufresne, J.-L., Fillmore, D. W., Forster, P. M., Galin, V. Y., Gohar, L. K., Ingram, W. J., Kratz, D. P., Lefebvre, M.-P., Li, J., Marquet, P., Oinas, V., Tsushima, Y., Uchiyama, T., and Zhong, W. Y.: Radiative forcing by well-mixed greenhouse gases: Estimates from cli- mate models in the Intergovernmental Panel on Climate Change (IPCC) Fourth Assessment Report (AR4), J. Geophys. Res., 111, D14317, https://doi.org/10.1029/2005JD006713, 2006.

Danilin, M. Y., Fahey, D. W., Schumann, U., Prather, M. J., Penner, J. E., Ko, M. K. W., Weisenstein, D. K., Jackman, C. H., Pitari, G., Köhler, I., Sausen, R., Weaver, C. J., Douglass, A. R., Connell, P. S., Kinnison, D. E., Dentener, F. J., Fleming, E. L., Berntsen, T. K., Isaksen, I. S. A., Haywood, J. M., and Kärcher, B.: Aviation Fuel Tracer Simulation: Model Intercomparison and Implications, Geophys. Res. Lett., 25, 3947-3950, 1998.

Dickinson, R. E.: Modeling climate changes due to carbon dioxide increases, in: Carbon Dioxide Review: 1982, edited by: Clark, W. C., Oxford University Press, New York, NY, 101-141, 1982.

Dietmüller, S., Ponater, M., Sausen, R., Hoinka, K.P., and Pechtl, S.: Contrails, natural clouds, and diurnal temperature range, J. Climate, 21, 5061-5075, https://doi.org/10.1175/2008JCLI2255.1, 2008.

Dietmüller, S., Jöckel, P., Tost, H., Kunze, M., Gellhorn, C., Brinkop, S., Frömming, C., Ponater, M., Steil, B., Lauer, A., and Hendricks, J.: A new radiation infrastructure for the Modular Earth Submodel System (MESSy, based on version 2.51), Geosci. Model Dev., 9, 2209-2222, https://doi.org/10.5194/gmd9-2209-2016, 2016.

Emde, C., Buras-Schnell, R., Kylling, A., Mayer, B., Gasteiger, J., Hamann, U., Kylling, J., Richter, B., Pause, C., Dowling, T., and Bugliaro, L.: The libRadtran software package for radiative transfer calculations (version 2.0.1), Geosci. Model Dev., 9, 1647-1672, https://doi.org/10.5194/gmd-9-1647-2016, 2016.

Forster, C., Stohl, A., James, P., and Thouret, V.: The residence times of aircraft emissions in the stratosphere using a mean emission inventory and emissions along actual flight tracks, J. Geophys. Res., 108, 8524, https://doi.org/10.1029/2002JD002515, 2003.

Forster, P. M., Freckleton, R. S., and Shine, K. P.: On aspects of the concept of radiative forcing, Clim. Dynam., 13, 547-560, 1997.

Frömming, C., Ponater, M., Dahlmann, K., Grewe, V., Lee, D. S., and Sausen, R.: Aviation-induced radiative forcing and surface temperature change in dependency of the emission altitude, J. Geophys. Res., 117, D19104, https://doi.org/10.1029/2012JD018204, 2012.

$\mathrm{Fu}, \mathrm{Q}$.: An accurate parameterisation of the solar radiative properties of cirrus clouds for climate models, J. Climate, 9, 20582082, 1996.

Fu, Q. and Liou, K. N.: On the correlated k-distribution method for radiative transfer in nonhomogeneous atmospheres, J. Atmos. Sci., 49, 2139-2156, 1992.

$\mathrm{Fu}$, Q. and Liou, K. N.: Parameterization of the radiative properties of cirrus clouds, J. Atmos. Sci., 50, 2008-2025, 1993.

Fu, Q., Yang, P., and Sun, W. B.: An accurate parameterization of the infrared radiative properties of cirrus clouds for climate models, J. Climate, 25, 2223-2237, 1998.

Gayet, J.-F., Shcherbakov, V., Voigt, C., Schumann, U., Schäuble, D., Jessberger, P., Petzold, A., Minikin, A., Schlager, H., Dubovik, O., and Lapyonok, T.: The evolution of microphysical and optical properties of an A380 contrail in the vortex phase, Atmos. Chem. Phys., 12, 6629-6643, https://doi.org/10.5194/acp12-6629-2012, 2012.

Goody, R. M. and Yung, Y. L.: Atmospheric Radiation - Theoretical Basis, Oxford Univ. Press, New York, USA, 519 pp., 1989. 
Hansen, J., Johnson, D., Lacis, A., Lebedeff, S., Lee, P., Rind, D., and Russell, G.: Climate impact of increasing atmospheric carbon dioxide, Science, 213, 957-966, https://doi.org/10.1126/science.213.4511.957, 1981.

Hansen, J., Russell, G., Lacis, A., Fung, I., Rind, D., and Stone, P.: Climate response times: Dependence on climate sensitivity and ocean mixing, Science, 229, 857-859, https://doi.org/10.1126/science.229.4716.857, 1985.

Hansen, J., Sato, M., and Ruedy, R.: Radiative forcing and climate response, J. Geophys. Res., 102, 6831-6684, 1997a.

Hansen, J., Sato, M., Ruedy, R., Lacis, A., Asamoah, K., Beckford, K., Borenstein, S., Brown, E., Cairns, B., Carlson, B., Curran, B., Castro, S. D., Druyan, L., Etwarrow, P., Ferede, T., Fox, M., Gaffen, D., Glascoe, J., Gordon, H., Hollandsworth, S., Jiang, X., Johnson, C., Lawrence, N., Lean, J., Lerner, J., Lo, K., Logan, J., Luckett, A., McCormick, M. P., McPeters, R., Miller, R., Minnis, P., Ramberran, I., Russell, G., Russell, P., Stone, P., Tegen, I., Thomas, S., Thomason, L., Thompson, A., Wilder, J., Willson, R., and Zawodny, J.: Forcings and chaos in interannual to decadal climate change, J. Geophys. Res., 102, 25679-25720, https://doi.org/10.1029/97JD01495, 1997b.

Hansen, J., Sato, M., Nazarenko, L. S., Ruedy, R., Lacis, A., Koch, D., Tegen, I., Hall, T., Shindell, D., Santer, B. D., Stone, P., Novakov, T., Thomason, L., Wang, R., Wang, Y., Jacob, D., Hollandsworth, S., Bishop, L., Logan, J., Thompson, A., Stolarski, R., Lean, J., Willson, R., Levitus, S., Antonov, J., Rayner, N., Parker, D., and Christy, J.: Climate forcings in Goddard Institute for Space Studies SI2000 simulations, J. Geophys. Res., 107, 4347, https://doi.org/10.1029/2001JD001143, 2002.

Hansen, J., Sato, M., Ruedy, R., Nazarenko, L., Lacis, A., Schmidt, G. A., Russell, G., Aleinov, I., Bauer, M., Bauer, S., Bell, N., Cairns, B., Canuto, V., Chandler, M., Cheng, Y., Del Genio, A., Faluvegi, G., Fleming, E., Friend, A., Hall, T., Jackman, C., Kelley, M., Kiang, N., Koch, D., Lean, J., Lerner, J., Lo, K., Menon, S., Miller, R., Minnis, P., Novakov, T., Oinas, V., Perlwitz, J., Perlwitz, J., Rind, D., Romanou, A., Shindell, D., Stone, P., Sun, S., Tausnev, N., Thresher, D., Wielicki, B., Wong, T., Yao, M., and Zhang, S.: Efficacy of climate forcings, J. Geophys. Res., 110, D18104, https://doi.org/10.1029/2005JD005776, 2005.

Haywood, J. M., Allan, R. P., Bornemann, J., Forster, P. M., Francis, P. N., Milton, S., Rädel, G., Rap, A., Shine, K. P., and Thorpe, R.: A case study of the radiative forcing of persistent contrails evolving into contrail-induced cirrus, J. Geophys. Res., 114, D24201, https://doi.org/10.1029/2009JD012650, 2009.

Hong, Y., Liu, G., and Li, J.-L. F.: Assessing the radiative effects of global ice clouds based on CloudSat and CALIPSO measurements, J. Climate, 29, 7651-7674, https://doi.org/10.1175/JCLID-15-0799.1, 2016.

Houghton, J. T., Jenkins, G. J., and Ephraums, J. J. (Eds.): Climate Change - The IPCC Scientific Assessment, Serial Climate Change - The IPCC Scientific Assessment, Serial, Intergovernmental Panel on Climate Change, Cambridge University Press, Cambridge, UK, 410 pp., 1990.

Huszar, P., Teyssèdre, H., Michou, M., Voldoire, A., Olivié, D. J. L., Saint-Martin, D., Cariolle, D., Senesi, S., Salas Y Melia, D., Alias, A., Karcher, F., Ricaud, P., and Halenka, T.: Modeling the present and future impact of aviation on climate: an AOGCM approach with online coupled chemistry, Atmos.
Chem. Phys., 13, 10027-10048, https://doi.org/10.5194/acp-1310027-2013, 2013.

Jacobson, M. Z., Wilkerson, J. T., Naiman, A. D.,and Lele, S. K.: The effects of aircraft on climate and pollution. Part I: Numerical methods for treating the subgrid evolution of discrete size- and composition-resolved contrails from all commercial flights worldwide, J. Comp. Phys., 230, 5115-5132, https://doi.org/10.1016/j.jcp.2011.03.031, 2011.

Jacobson, M. Z., Wilkerson, J. T., Naiman, A. D., and Lele, S. K.: The effects of aircraft on climate and pollution. Part II: 20year impacts of exhaust from all commercial aircraft worldwide treated individually at the subgrid scale, Faraday Discussions, 165, 369-382, https://doi.org/10.1039/c3fd00034f, 2013.

Jensen, E. J., Kinne, S., and Toon, O. B.: Tropical cirrus cloud radiative forcing: Sensitivity studies, Geophys. Res. Lett., 21, 20232026, https://doi.org/10.1029/94GL01358, 1994.

Joshi, M., Shine, K., Ponater, M., Stuber, N., Sausen, R., and Li, L.: A comparison of climate response to different radiative forcings in three general circulation models: Towards an improved metric of climate change, Clim. Dynam., 20, 843-854, https://doi.org/10.1007/s00382-003-0305-9, 2003.

Kato, S., Ackerman, T. P., Mather, J. H., and Clothiaux, E. E.: The kdistribution method and correlated-k approximation for a shortwave radiative transfer model, J. Quant. Spectrosc. Ra., 62, 109121, 1999.

Khvorostyanov, V. and Sassen, K.: Cloud model simulation of a contrail case study: Surface cooling against upper tropospheric warming, Geophys. Res. Lett., 25, 2145-2148, 1998.

Kuhn, P. M.: Airborne observations of contrail effects on the thermal radiation budget, J. Atmos. Sci., 27, 937-943, 1970.

Kvalevåg, M. M. and Myhre, G.: Human impact on direct and diffuse solar radiation during the industrial era, J. Climate, 20, 4874-4883, https://doi.org/10.1175/JCLI4277.1, 2007.

Lee, D. S., Fahey, D. W., Forster, P. M., Newton, P. J., Wit, R. C. N., Lim, L. L., Owen, B., and Sausen, R.: Aviation and global climate change in the 21 st century, Atmos. Environ., 43, 3520 3537, https://doi.org/10.1016/j.atmosenv.2009.04.024, 2009.

Lee, J., Yang, P., Dessler, A. E., Gao, B.-C., and Platnick, S.: Distribution and radiative forcing of tropical thin cirrus clouds, J. Atmos. Sci., 66, 3721-3731, https://doi.org/10.1175/2009JAS3183.1, 2009.

Liou, K. N.: Influence of cirrus clouds on weather and climate processes: A global perspective, Mon. Weather Rev., 114, 11671199, 1986.

Liou, K.-N. and Ou, S.-C. S.: Theory of equilibrium temperatures in radiative-turbulent atmospheres, J. Atmos. Sci., 40, 214-229, 1983.

Liou, K. N., Ou, S. C., and Koenig, G.: An investigation of the climatic effect of contrail cirrus, in: Air Traffic and the Environment - Background, Tendencies and Potential Global Atmospheric Effects, edited by: Schumann, U., Lecture Notes in Engineering, Springer Berlin, Germany, 154-169, 1990.

Lund, M. T., Aamaas, B., Berntsen, T., Bock, L., Burkhardt, U., Fuglestvedt, J. S., and Shine, K. P.: Emission metrics for quantifying regional climate impacts of aviation, Earth Syst. Dynam., 8, 547-563, https://doi.org/10.5194/esd-8-547-2017, 2017.

Manabe, S. and Stouffer, R. J.: Sensitivity of a global climate model to an increase of $\mathrm{CO}_{2}$ concentration in the atmosphere, J. Geophys. Res., 85, 5529-5554, 1980. 
Manabe, S. and Strickler, R. F.: Thermal equilibrium of the atmosphere with a convective adjustment, J. Geophys. Res., 21, 361385, 1964.

Manabe, S. and Wetherald, R. T.: Thermal equilibrium of the atmosphere with a given distribution of relative humidity, J. Atmos. Sci., 24, 241-259, 1967.

Markowicz, K. M. and Witek, M.: Sensitivity study of global contrail radiative forcing due to particle shape, J. Geophys. Res., 116, D23203, https://doi.org/10.1029/2011JD016345, 2011.

Marquart, S., Ponater, M., Mager, F., and Sausen, R.: Future development of contrail cover, optical depth and radiative forcing: Impacts of increasing air traffic and climate change, J. Climate, 16, 2890-2904, 2003.

Mayer, B. and Kylling, A.: Technical note: The libRadtran software package for radiative transfer calculations - description and examples of use, Atmos. Chem. Phys., 5, 1855-1877, https://doi.org/10.5194/acp-5-1855-2005, 2005.

Meerkötter, R., Schumann, U., Doelling, D. R., Minnis, P., Nakajima, T., and Tsushima, Y.: Radiative forcing by contrails, Ann. Geophys., 17, 1080-1094, https://doi.org/10.1007/s00585-9991080-7, 1999.

Minnis, P.: Reply, J. Climate, 18, 2783-2784, 2005.

Minnis, P., Schumann, U., Doelling, D. R., Gierens, K., and Fahey, D. W.: Global distribution of contrail radiative forcing, Geophys. Res. Lett., 26, 1853-1856, https://doi.org/10.1029/1999GL900358, 1999.

Minnis, P., Bedka, S. T., Duda, D. P., Bedka, K. M., Chee, T., Ayers, J. K., Palikonda, R., Spangenberg, D. A., Khlopenkov, K. V., and Boeke, R.: Linear contrail and contrail cirrus properties determined from satellite data, Geophys. Res. Lett., 40, 3220-3226, https://doi.org/10.1002/grl.50569, 2013.

Möller, F. and Manabe, S.: Über das Strahlungsgleichgewicht der Atmosphäre, Z. Meteorol., 15, 3-8, 1961.

Myhre, G. and Stordal, F.: On the tradeoff of the solar and thermal infrared impact of contrails, Geophys. Res. Lett., 28, 3119-3122, https://doi.org/10.1029/2001GL013193, 2001.

Myhre, G., Highwood, E. J., Shine, K. P., and Stordal, F.: New estimates of radiative forcing due to well mixed greenhouse gases, Geophys. Res. Lett., 26, 2715-2718, https://doi.org/10.1029/98GL01908, 1998.

Myhre, G., Kvalevag, M., Rädel, G., Cook, J., Shine, K. P., Clark, H., Karcher, F., Markowicz, K., Karda, A., Wolkenberg, O., Balkanski, Y., Ponater, M., Forster, P., Rap, A., and Rodriguez de Leon, R.: Intercomparison of radiative forcing calculations of stratospheric water vapour and contrails, Meteorol. Z., 18, 585596, https://doi.org/10.1127/0941-2948/2009/0411, 2009.

Myhre, G., Shindell, D., Bréon, F.-M., Collins, W., Fuglestvedt, J., Huang, J., Koch, D., Lamarque, J.-F., Lee, D., Mendoza, B., Nakajima, T., Robock, A., Stephens, G., Takemura, T., and Zhang, H.: Anthropogenic and natural radiative forcing, in: Climate Change 2013: The Physical Science Basis. Contribution of Working Group I to the Fifth Assessment Report of the Intergovernmental Panel on Climate Change, edited by: Stocker, T. F., Qin, D., Plattner, G.-K., Tignor, M., Allen, S. K., Boschung, J., Nauels, A., Xia, Y., Bex, V., and Midgley, P. M., Cambridge University Press, Cambridge, UK and New York, NY, USA., 659$740,2013$.

Ogura, T., Webb, M. J., Watanabe, M., Lambert, F. H., Tsushima, Y., and Sekiguchi, M.: Importance of instantaneous radiative forc- ing for rapid tropospheric adjustment, Clim. Dynam., 43, 14091421, https://doi.org/10.1007/s00382-013-1955-x, 2014.

Olivié, D. J. L., Cariolle, D., Teyssèdre, H., Salas, D., Voldoire, A., Clark, H., Saint-Martin, D., Michou, M., Karcher, F., Balkanski, Y., Gauss, M., Dessens, O., Koffi, B., and Sausen, R.: Modeling the climate impact of road transport, maritime shipping and aviation over the period 1860-2100 with an AOGCM, Atmos. Chem. Phys., 12, 1449-1480, https://doi.org/10.5194/acp12-1449-2012, 2012.

Penner, J. E., Lister, D. H., Griggs, D. J., Dokken, D. J., and McFarland, M.: Aviation and the Global Atmosphere - A Special Report of IPCC Working Groups I and III. Intergovernmental Panel on Climate Change, Cambridge University Press, Cambridge, UK, 365 pp., 1999.

Plass, G. N., Kattawar, G. W., and Catchings, F. E.: Matrix operator theory of radiative transfer. 1: Rayleigh scattering, Appl. Opt., 12, 314-329, https://doi.org/10.1364/AO.12.000314 1973.

Ponater, M., Brinkop, S., Sausen, R., and Schumann, U.: Simulating the global atmospheric response to aircraft water vapour emissions and contrails: a first approach using a GCM, Ann. Geophys., 14, 941-960, https://doi.org/10.1007/s00585-996-0941-6, 1996.

Ponater, M., Marquart, S., and Sausen, R.: Contrails in a comprehensive global climate model: Parameterization and radiative forcing results, J. Geophys. Res., 107, 4164, https://doi.org/10.1029/2001JD000429, 2002.

Ponater, M., Marquart, S., Sausen, R., and Schumann, U.: On contrail climate sensitivity, Geophys. Res. Lett., 32, L10706, https://doi.org/10.1029/2005g1022580, 2005.

Ponater, M., Pechtl, S., Sausen, R., Schumann, U., and Hüttig, G.: Potential of the cryoplane technology to reduce aircraft climate impact: A state-of-the-art assessment, Atmos. Environ., 40, 6928-6944, https://doi.org/10.1016/j.atmosenv.2006.06.036, 2006a.

Ponater, M., Grewe, V., Sausen, R., Schumann, U., Pechtl, S., Highwood, E. J., and Stuber, N.: Climate sensitivity of radiative impacts from transport systems, in: Proceedings of an International Conference on Transport, Atmosphere and Climate (TAC), edited by: Sausen, R., Blum, A., Lee, D. S., and Brüning, C., University of Manchester and DLR Oberpfaffenhofen, 190-196, available at: http://elib.dlr.de/54467/ (last access: 18 November 2017), 2006b.

Ramanathan, V. and Coakley, J. A.: Climate modeling through radiative-convective models, Rev. Geophys., 16, 465-489, 1978.

Ramanathan, V. and Dickinson, R. E.: The role of stratospheric ozone in the zonal and seasonal radiative energy balance of the Earth-troposphere system, J. Atmos. Sci., 36, 1084-1104, 1979.

Rap, A., Forster, P. M., Haywood, J. M., Jones, A., and Boucher, O.: Estimating the climate impact of linear contrails using the UK Met Office climate model, Geophys. Res. Lett., 37, L20703, https://doi.org/10.1029/2010GL045161, 2010a.

Rap, A., Forster, P. M., Jones, A., Boucher, O., Haywood, J. M., Bellouin, N., and Leon, R. R. D.: Parameterization of contrails in the UK Met Office Climate Model, J. Geophys. Res., 115, D10205, https://doi.org/10.1029/2009JD012443, 2010b.

Reinking, R.: Insolation reduction by contrails, Weather, 23, 171$173,1968$. 
Rind, D., Lonergan, P., and Shah, K.: Modeled impact of cirrus cloud increases along aircraft flight paths, J. Geophys. Res., 105, 19927-19940, https://doi.org/10.1029/1999JD901160, 2000.

Rossow, W. B. and Zhang, Y.-C.: Calculation of surface and top of atmosphere radiative fluxes from physical quantities based on ISCCP data sets. Part 2: Validation and first results, J. Geophys. Res., 100, 1167-1197, 1995.

Rotstayn, L. D. and Penner, J. E.: Indirect aerosol forcing, quasi forcing, and climate response, J. Climate, 14, 2960-2975, 2001.

Sassen, K.: Contrail-cirrus and their potential for regional climate change, B. Am. Meteorol. Soc., 78, 1885-1903, 1997.

Schneider, S. H. and Dickinson, R. E.: Climate modeling, Rev. Geophys. Space Phys., 12, 447-493, 1974.

Schumann, U. and Graf, K.: Aviation-induced cirrus and radiation changes at diurnal timescales, J. Geophys. Res., 118, 2404-2421, https://doi.org/10.1002/jgrd.50184, 2013.

Schumann, U. and Heymsfield, A.: On the lifecycle of individual contrails and contrail cirrus, Meteor. Monogr., 58, 3.1-3.24, https://doi.org/10.1175/AMSMONOGRAPHS-D-160005.1, 2017.

Schumann, U., Mayer, B., Graf, K., and Mannstein, H.: A parametric radiative forcing model for contrail cirrus, J. Appl. Meteorol. Clim., 51, 1391-1406, https://doi.org/10.1175/JAMC-D-110242.1, 2012.

Schumann, U., Penner, J. E., Chen, Y., Zhou, C., and Graf, K.: Dehydration effects from contrails in a coupled contrailclimate model, Atmos. Chem. Phys., 15, 11179-11199, https://doi.org/10.5194/acp-15-11179-2015, 2015.

Schumann, U., Baumann, R., Baumgardner, D., Bedka, S. T., Duda, D. P., Freudenthaler, V., Gayet, J.-F., Heymsfield, A. J., Minnis, P., Quante, M., Raschke, E., Schlager, H., Vázquez-Navarro, M., Voigt, C., and Wang, Z.: Properties of individual contrails: a compilation of observations and some comparisons, Atmos. Chem. Phys., 17, 403-438, https://doi.org/10.5194/acp-17-4032017, 2017.

Shindell, D., Schulz, M., Ming, Y., Takemura, T., Faluvegi, G., and Ramaswamy, V.: Spatial scales of climate response to inhomogeneous radiative forcing, J. Geophys. Res., 115, D19110, https://doi.org/10.1029/2010JD014108, 2010.

Shine, K. P. and Sinha, A.: Sensitivity of the Earth's climate to height-dependent changes in the water vapour mixing ratio, Nature, 354, 382-384, https://doi.org/10.1038/354382a0, 1991.

Shine, K. P., Fouquart, Y., Ramaswamy, V., Solomon, S., and Srinivasan, J.: Radiative Forcing, in: Climate Change 1994: Radiative Forcing of Climate Change and An Evaluation of the IPCC IS92 Emission Scenarios, edited by: Houghton, J. T., Filho, L. G. M., Bruce, J., Lee, H., Callander, B. A., Haites, E., Harris, N., and Maskell, K., Cambridge University Press, Cambridge, UK, 164203, 1994

Shine, K. P., Cook, J., Highwood, E. J., and Joshi, M. M.: An alternative to radiative forcing for estimating the relative importance of climate change mechanisms, Geophys. Res. Lett., 30, 2047, https://doi.org/10.1029/2003GL018141, 2003.

Sinha, A. and Shine, K. P.: A one-dimensional study of possible cirrus cloud feedbacks, J. Climate, 7, 158-173, 1994.

Solomon, S., Rosenlof, K. H., Portmann, R. W., Daniel, J. S., Davis, S. M., Sanford, T. J., and Plattner, G.-K.: Contributions of stratospheric water vapor to decadal changes in the rate of global warming, Science, 327, 1219-1223, https://doi.org/10.1126/science.1182488, 2010.

Spangenberg, D. A., Minnis, P., Bedka, S. T., Palikonda, R., Duda, D. P., and Rose, F. G.: Contrail radiative forcing over the Northern Hemisphere from 2006 Aqua MODIS data, Geophys. Res. Lett., 40, 595-600, https://doi.org/10.1002/grl.50168, 2013.

Stackhouse, P. W. and Stephens, G. L.: A theoretical and observational study of the radiative properties of cirrus: Results from FIRE 1986, J. Atmos. Sci., 48, 2044-2059, 1991.

Stamnes, K., Tsay, S., Wiscombe, W., and Jayaweera, K.: A numerically stable algorithm for discrete-ordinate-method radiative transfer in multiple scattering and emitting layered media, Appl. Opt., 27, 2502-2509, 1998.

Stephens, G. L.: The parameterization of radiation for numerical weather prediction and climate models, Mon Weather Rev., 112, 826-867, 1984.

Stephens, G. L.: Cloud feedbacks in the climate system: A critical review, J. Climate, 18, 237-273, https://doi.org/10.1175/JCLI3243.1, 2005.

Stephens, G. L. and Webster, P. J.: Clouds and climate: Sensitivity of simple systems, J. Atmos. Sci., 38, 235-247, 1981.

Stevens, B. and Bony, S.: Water in the atmosphere, Physics Today, 66, 29-34, https://doi.org/10.1063/PT.3.2009, 2013.

Stone, P. H.: The effect of large-scale eddies on climate change, J. Atmos. Sci., 30, 521-529, 1973.

Strauss, B., Meerkoetter, R., Wissinger, B., Wendling, P., and Hess, M.: On the regional climatic impact of contrails: microphysical and radiative properties of contrails and natural cirrus clouds, Ann. Geophys., 15, 1457-1467, https://doi.org/10.1007/s00585997-1457-4, 1997.

Stuber, N., Sausen, R., and Ponater, M.: Stratosphere adjusted radiative forcing calculations in a comprehensive climate model, Theor. Appl. Climatol., 68, 125-135, 2001.

Stuber, N., Ponater, M., and Sausen, R.: Why radiative forcing might fail as a predictor of climate change, Clim. Dynam., 24, 497-510, https://doi.org/10.1007/s00382-004-0497-7, 2005.

Vallis, G. K.: Atmospheric and Oceanic Fluid Dynamics, Cambridge Univ. Press, Cambridge, UK, 2006.

Vázquez-Navarro, M., Mannstein, H., and Kox, S.: Contrail life cycle and properties from 1 year of MSG/SEVIRI rapid-scan images, Atmos. Chem. Phys., 15, 8739-8749, https://doi.org/10.5194/acp-15-8739-2015, 2015.

Weihs, P., Rennhofer, M., Baumgartner, D. J., Gadermaier, J., Wagner, J. E., Gehring, J. E., and Laube, W.: Potential impact of contrails on solar energy gain, Atmos. Meas. Tech., 8, 1089-1096, https://doi.org/10.5194/amt-8-1089-2015, 2015.

Wendisch, M., Pilewskie, P., Pommier, J., Howard, S., Yang, P., Heymsfield, A. J., Schmitt, C. G., Baumgardner, D., and Mayer, B.: Impact of cirrus crystal shape on solar spectral irradiance: A case study for subtropical cirrus, J. Geophys. Res., 110, D03202, https://doi.org/10.1029/2004JD005294, 2005.

Wetherald, R. T. and Manabe, S.: The effects of doubling the $\mathrm{CO}_{2}$ concentration on the climate of a general circulation model, $\mathrm{J}$ Atmos. Sci., 32, 3-15, 1975.

Wyser, K. and Ström, J.: A possible change in cloud radiative forcing due to aircraft exhaust, Geophys. Res. Lett., 25, 1673-1676, 1998.

Yang, P., Liou, K. N., Bi, L., Liu, C., Yi, B. Q., and Baum, B. A.: On the radiative properties of ice clouds: Light scattering, remote 
sensing, and radiation parameterization, Adv. Atmos. Sci., 32, 32-63, https://doi.org/10.1007/s00376-014-0011-z, 2015.

Zhang, Y., Macke, A., and Albers, F.: Effect of crystal size spectrum and crystal shape on stratiform cirrus radiative forcing, Atmos. Res., 52, 59-75, https://doi.org/10.1016/S0169-8095(99)00026$5,1999$.
Zhu, X.: Radiative damping revisited: Parameterization of damping rate in the middle atmosphere, J. Atmos. Sci., 50, 3008-3021, 1993. 